\title{
Improved Scale-up Synthesis and Purification of Clinical Asthma Candidate MIDD0301
}

Daniel E. Knutson, $\uparrow$ M.S. Rashid Roni,$\uparrow$ Md Yeunus Mian, $\uparrow$ James M. Cook, $\uparrow$ Douglas C. Stafford $, \uparrow, \|$ and Leggy A. Arnold ${ }^{*, \dagger}, \|$

$\dagger$ Department of Chemistry and Biochemistry and the Milwaukee Institute for Drug Discovery, University of Wisconsin-Milwaukee, Milwaukee, Wisconsin 53201, United States

॥Pantherics Incorporated, La Jolla, California 92037, United States

*Corresponding Author, Department of Chemistry and Biochemistry, University of Wisconsin-Milwaukee, Milwaukee, Wisconsin 53201, arnold2@uwm.edu

\section{Contents}

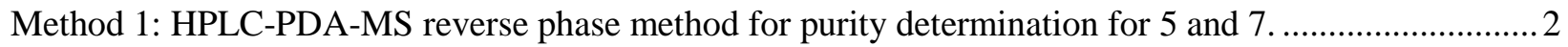

Method 2: HPLC-PDA-MS reverse phase method for purity determination of MIDD0301 ...................... 3

Method 3: HPLC-DAD normal phase method for optical purity determination of 5 ............................... 3

Method 4: HPLC-DAD normal phase method for optical purity determination of 7 ................................ 3

Method 5: HPLC-DAD normal phase method for optical purity determination of MIDD0301 .................. 3

HPLC chromatogram $(245 \mathrm{~nm})$ for product 5 (method 1) ...................................................................... 4

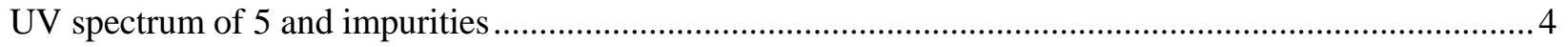

Mass spectrum of 5 (RT 8.07 min, method 1) (97.28\% absolute area) ..................................................5

Mass spectrum of impurities for synthesis of 5: (RT 9.04, method 1) ( $0.76 \%$ absolute area) .....................5

Mass spectrum of 5b (RT 9.37 min, method 1) (1.96\% absolute area) .................................................... 6

Optical purity of 5 determined by HPLC (method 3$)$.......................................................................... 6

HPLC chromatogram $(245 \mathrm{~nm})$ for product 7 (method 1) ................................................................... 7

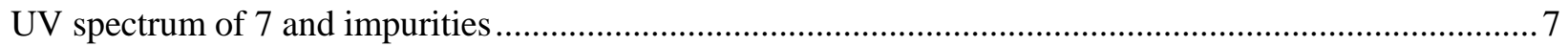

Mass spectrum of 7 (RT 9.55 min, method 1) (97.20\% absolute area) ................................................... 8

Mass spectrum of 7a (RT 11.24 min, method 1) (1.36\% absolute area) ................................................ 8

Mass spectrum of 7b (RT 11.54 min, method 1) (1.44\% absolute area) ................................................. 9

Optical purity of 7 determined by HPLC (Method 4) 99.0\% ee ............................................................. 9

HPLC chromatogram (245 nm) for product MIDD0301 (method 2) ...................................................... 10

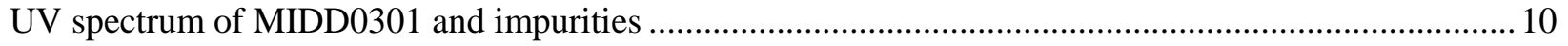

Mass spectrum of MIDD0301 (RT 3.10 min, method 2) (98.86\% absolute area) ...................................11

Mass spectrum of MIDD0301a (RT 3.72 min, method 2) (1.14\% absolute area) ................................... 11

Optical purity of MIDD0301 determined by HPLC (Method 5) >99.2 \% ee ......................................... 12 


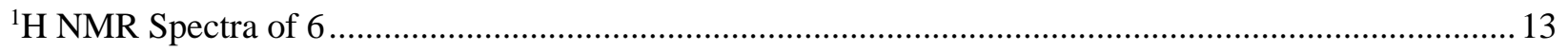

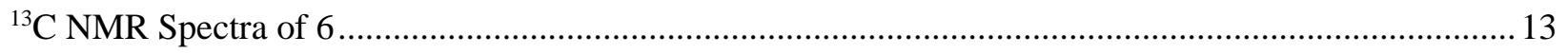

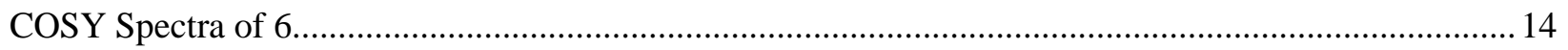

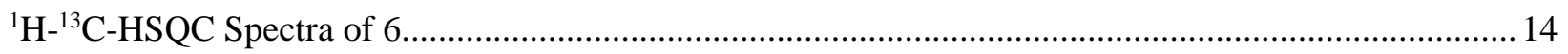

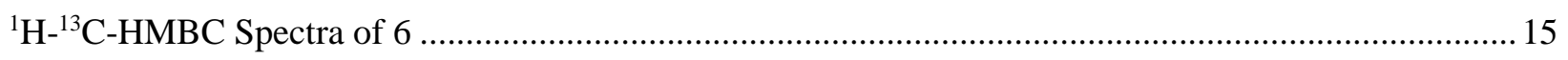

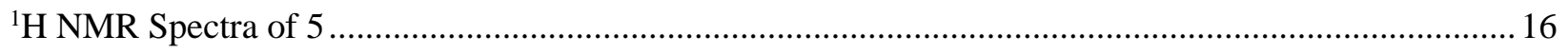

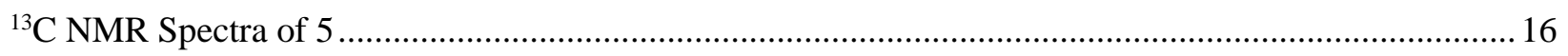

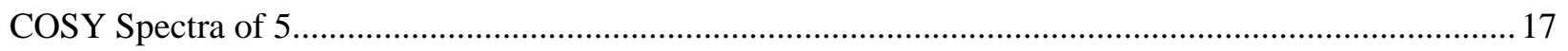

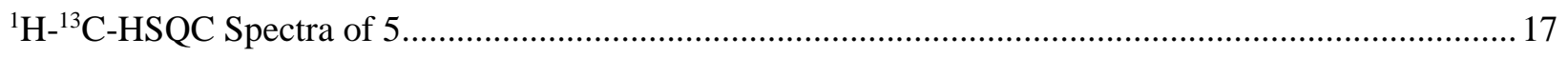

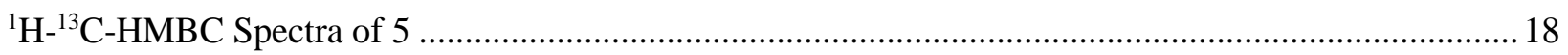

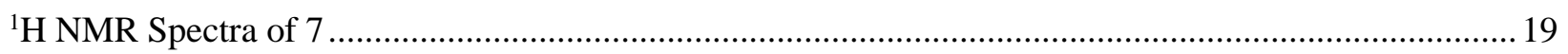

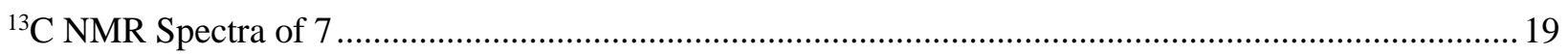

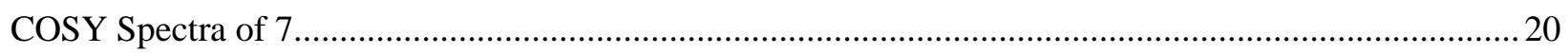

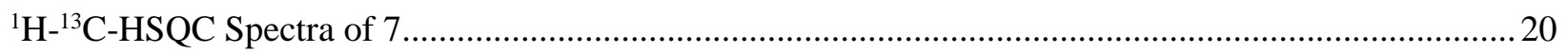

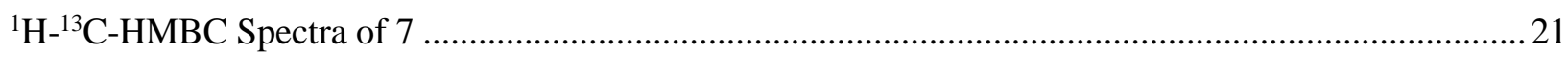

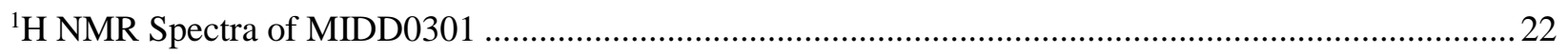

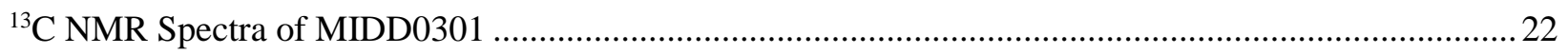

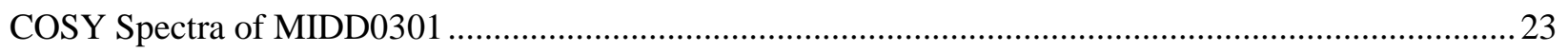

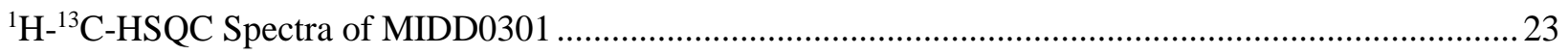

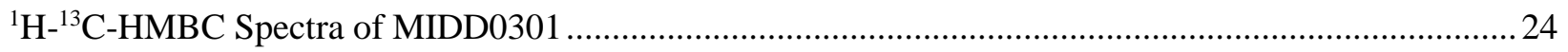

Method 1: HPLC-PDA-MS reverse phase method for purity determination for 5 and 7.

Purity was determined using absolute area $\% .0 .1 \%$ formic acid in methanol and $0.1 \%$ formic acid in water was used as the mobile phase. High performance liquid chromatography (Shimadzu Nexara series) with a Photo Diode Array detector (PDA, Shimadzu SPD-M30A) and a single quadrupole mass analyzer (LCMS 2020, Shimadzu, Kyoto, Japan) was used. Analytes were separated using a Restek Pinnacle-C18 (4.6 mm x $50 \mathrm{~mm}, 5 \mu \mathrm{m}$ particle size) column with gradient elution at a flow rate of $0.8 \mathrm{~mL} / \mathrm{min}$. The time program of mobile phase elution is exhibited in Table 1. Data were acquired by PDA having a range of 190-700 $\mathrm{nm}$ but $254 \mathrm{~nm}$ was used for detection. The mass spectrometer was equipped with a DUIS ionization probe (having both electrospray and atmospheric Table 1. Time program for method 1.

\begin{tabular}{|c|c|}
\hline $\begin{array}{c}\text { Time } \\
(\text { min })\end{array}$ & $\begin{array}{c}\text { Mobile Phase B\% } \\
(0.1 \% \text { formic acid in } \\
\text { Methanol })\end{array}$ \\
\hline 0 & 40 \\
\hline 3.5 & 55 \\
\hline 5.5 & 55 \\
\hline 10 & 70 \\
\hline 11 & 100 \\
\hline 12 & 100 \\
\hline 13 & 40 \\
\hline 15 & 40 \\
\hline
\end{tabular}
pressure ionization). The mass range was set $\mathrm{m} / \mathrm{z} 200-800$ for both positive and negative mode. Scan speed was $5000 \mathrm{u} / \mathrm{sec}$, interface, desolvation line and heat block temperature were $350^{\circ} \mathrm{C}, 250^{\circ} \mathrm{C}$ and $400^{\circ} \mathrm{C}$, respectively. Nebulizing gas flow was $1.5 \mathrm{~L} / \mathrm{min}$ and drying gas flow was $15 \mathrm{~L} / \mathrm{min}$. 
Method 2: HPLC-PDA-MS reverse phase method for purity determination of MIDD0301

Purity was determined using absolute area \%. $0.1 \%$ formic acid in methanol and $0.1 \%$ formic acid in water was used as the mobile phase. High performance liquid chromatography (Shimadzu Nexara series) with a Photo Diode Array detector (PDA, Shimadzu SPD-M30A) and a single quadrupole mass analyzer (LCMS 2020, Shimadzu, Kyoto, Japan) was used. Analytes were separated using a Restek Pinnacle-C18 (4.6 mm x $50 \mathrm{~mm}, 5 \mu \mathrm{m}$ particle size) column with gradient elution at a flow rate of $0.8 \mathrm{~mL} / \mathrm{min}$. The time program of mobile phase elution is exhibited in Table 2. Data were acquired by PDA having a range of 190-700 nm but $254 \mathrm{~nm}$ was used for detection. The mass spectrometer was equipped with a DUIS

Table 2. Time program for method 2

\begin{tabular}{|c|c|}
\hline $\begin{array}{c}\text { Time } \\
(\min )\end{array}$ & $\begin{array}{c}\text { Mobile Phase B\% } \\
(0.1 \% \text { formic acid in } \\
\text { Methanol })\end{array}$ \\
\hline 0 & 40 \\
\hline 2.7 & 80 \\
\hline 3.7 & 100 \\
\hline 4.2 & 100 \\
\hline 5 & 40 \\
\hline 7 & 40 \\
\hline
\end{tabular}
ionization probe (having both electrospray and atmospheric pressure ionization). The mass range was set $\mathrm{m} / \mathrm{z} 200-800$ for both positive and negative mode. Scan speed was $5000 \mathrm{u} / \mathrm{sec}$, interface, desolvation line and heat block temperature were $350^{\circ} \mathrm{C}, 250^{\circ} \mathrm{C}$ and $400^{\circ} \mathrm{C}$, respectively. Nebulizing gas flow was 1.5 $\mathrm{L} / \mathrm{min}$ and drying gas flow was $15 \mathrm{~L} / \mathrm{min}$.

\section{Method 3: HPLC-DAD normal phase method for optical purity determination of 5}

An isocratic mixture of $92 \%$ n-hexane and $8 \%$ ethanol was used as the mobile phase to resolve the R and S enantiomers of 5. An Agilent 1100 HPLC system consisting of a quaternary pump, autosampler and a DAD detector was used in combination with a Pirkle Whelk-01 column $(4.6 \mathrm{~mm}$ x $25 \mathrm{~cm}, 5 \mu \mathrm{m}$ particle size). A racemic mixture was used for the verification of the method. The $\mathrm{S}$ enantiomer eluted at $10.12 \mathrm{~min}$ and the $\mathrm{R}$ enantiomer at $11.89 \mathrm{~min}$. The resolution between peaks was 2.8 . The flow rate was $1 \mathrm{~mL} / \mathrm{min}$ and DAD wavelength range was set at $200-400 \mathrm{~nm}$. A $254 \mathrm{~nm}$ wavelength was used for relative $\%$ area determination and the enantiomeric excess was calculated using \% ee $=(\mathrm{R}-\mathrm{S}) /(\mathrm{R}+\mathrm{S}) \times 100$.

\section{Method 4: HPLC-DAD normal phase method for optical purity determination of 7}

An isocratic mixture of $65 \%$ n-hexane and $35 \%$ ethanol was used as the mobile phase to resolve the R and $\mathrm{S}$ enantiomers of 7. An Agilent 1100 HPLC system consisting of a quaternary pump, autosampler, and a DAD detector was used in combination with a Pirkle Whelk-01 column $(4.6 \mathrm{~mm}$ x $25 \mathrm{~cm}, 5 \mu \mathrm{m}$ particle size). A racemic mixture was used for the verification of the method. The $\mathrm{R}$ enantiomer eluted at $13.88 \mathrm{~min}$ and the $\mathrm{S}$ enantiomer at $23.69 \mathrm{~min}$. The resolution between peaks was 5.6. The flow rate was $1 \mathrm{~mL} / \mathrm{min}$ and the DAD wavelength range was set at $200-400 \mathrm{~nm}$. A $254 \mathrm{~nm}$ wavelength was used for relative $\%$ area determination and the enantiomeric excess was calculated using \% ee $=(\mathrm{R}-\mathrm{S}) /(\mathrm{R}+\mathrm{S}) \times 100$.

\section{Method 5: HPLC-DAD normal phase method for optical purity determination of MIDD0301}

An isocratic mixture of $90 \% \mathrm{n}$-hexane and $10 \%$ ethanol was used as the mobile phase to resolve the $\mathrm{R}$ and $\mathrm{S}$ enantiomers of MIDD0301. An Agilent 1100 HPLC system consisting of a quaternary pump, autosampler, and a DAD detector was used in combination with a Chiralpak IB-N3 (4.6 mm x $15 \mathrm{~cm}, 3$ $\mu \mathrm{m})$. A racemic mixture was used for the verification of the method. The R enantiomer eluted at $9.60 \mathrm{~min}$ and the $\mathrm{S}$ enantiomer at $12.5 \mathrm{~min}$. The resolution between peaks was 4.9 . The flow rate was $1 \mathrm{~mL} / \mathrm{min}$ and the DAD wavelength range was set at $200-400 \mathrm{~nm}$. A $254 \mathrm{~nm}$ wavelength was used for relative $\%$ area determination and the enantiomeric excess was calculated using \% ee $=(\mathrm{R}-\mathrm{S}) /(\mathrm{R}+\mathrm{S}) \times 100$. 
HPLC chromatogram $(245 \mathrm{~nm})$ for product $5($ method 1)

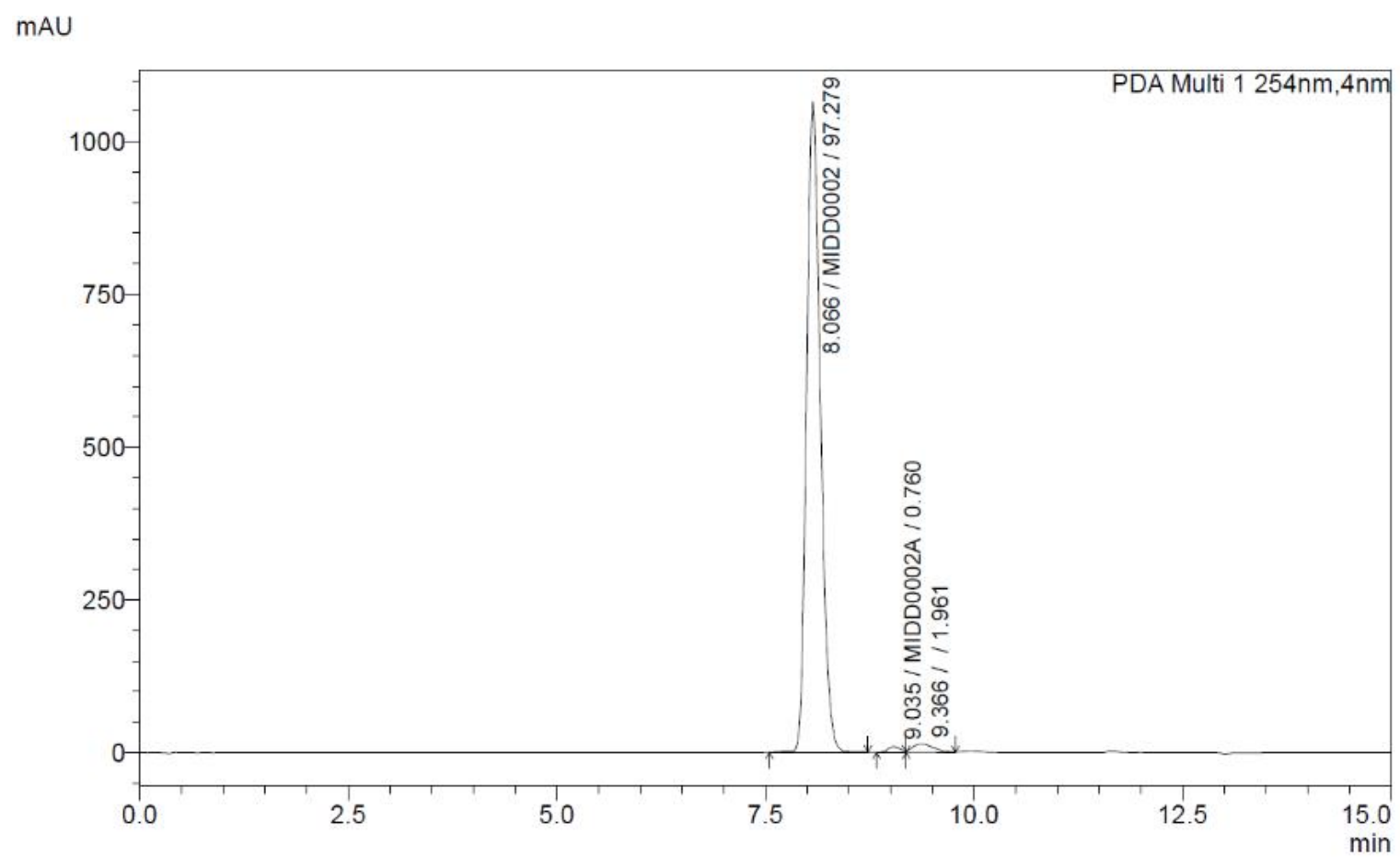

\section{UV spectrum of 5 and impurities}

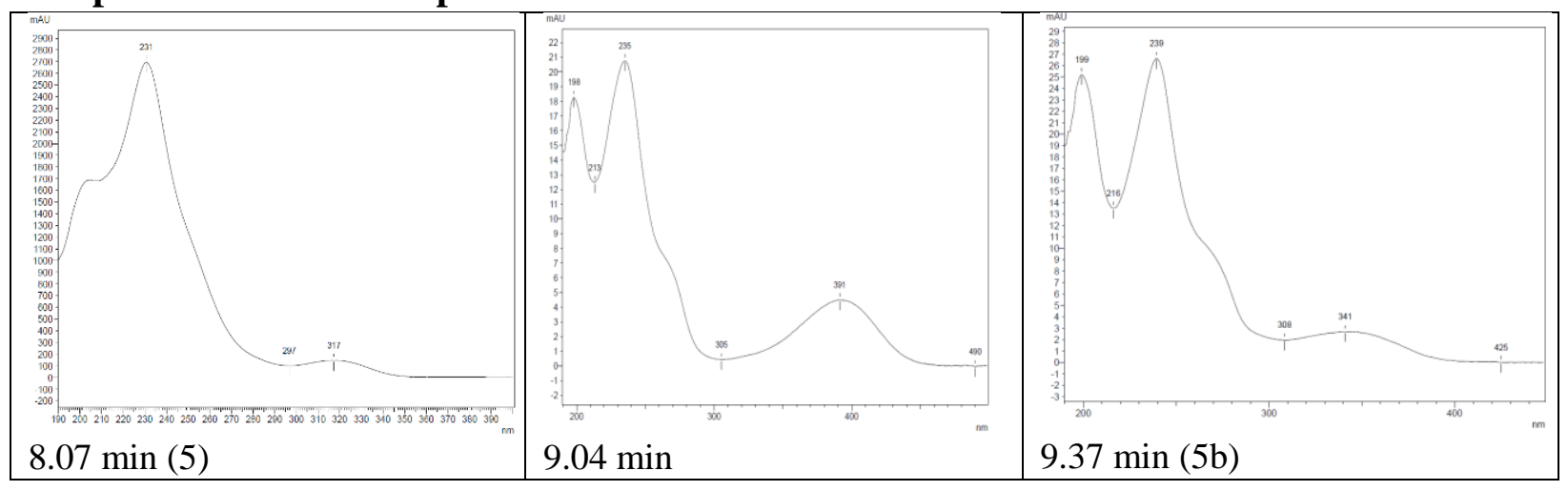


Mass spectrum of 5 (RT 8.07 min, method 1) (97.28\% absolute area)

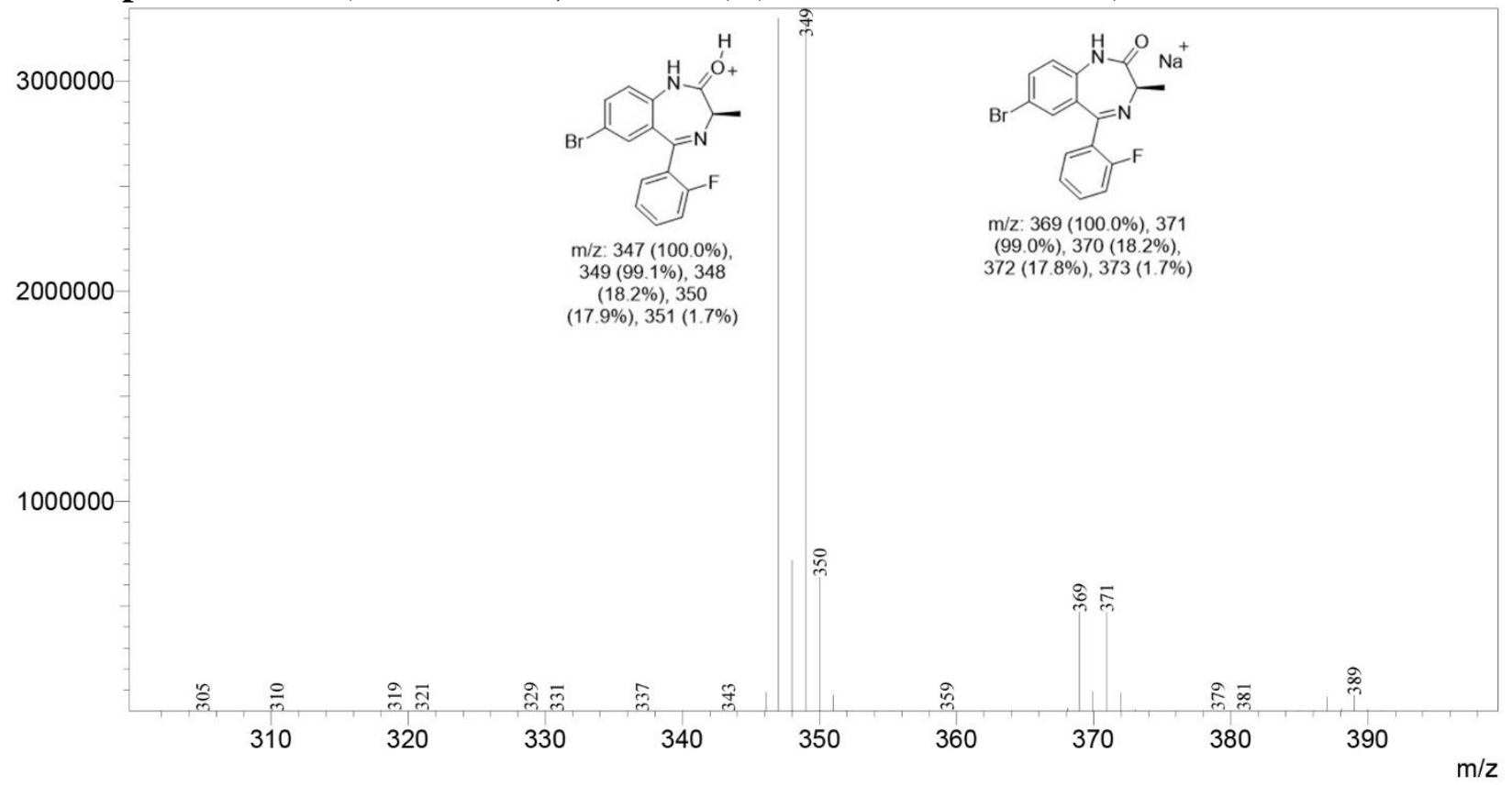

Mass spectrum of impurities for synthesis of 5: (RT 9.04, method 1) (0.76\% absolute area)

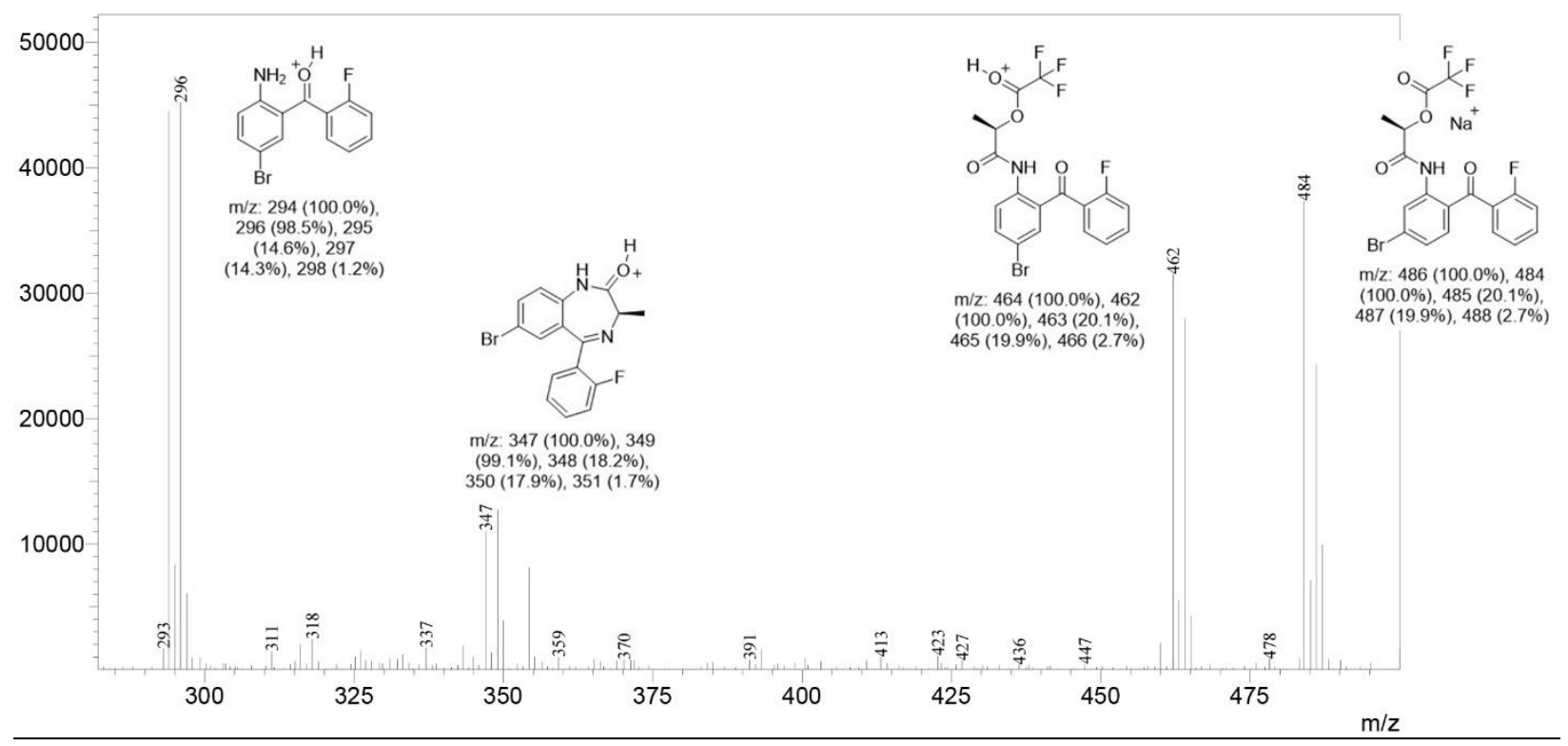


Mass spectrum of $5 \mathrm{~b}$ (RT $9.37 \mathrm{~min}$, method 1) (1.96\% absolute area)

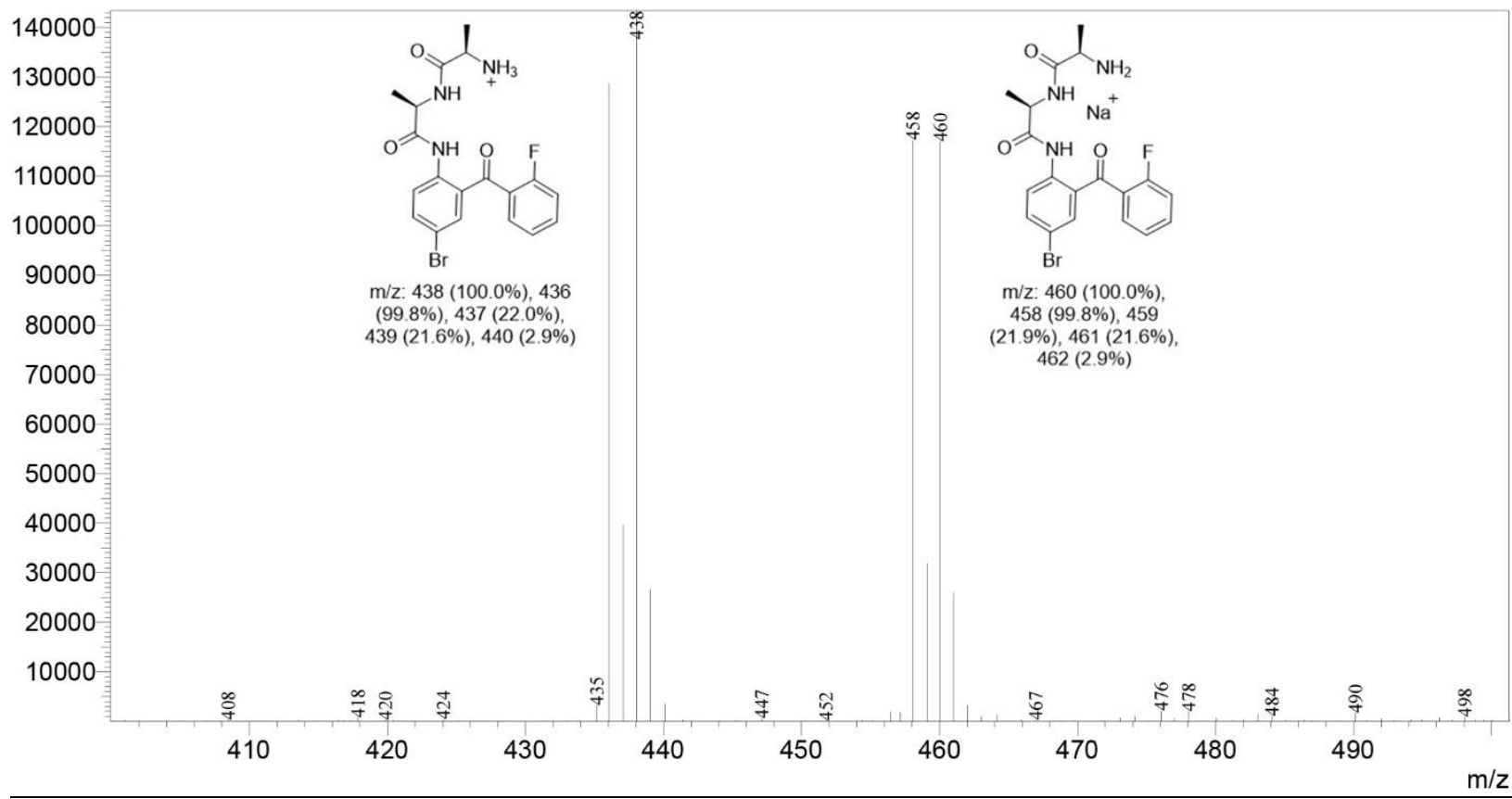

Optical purity of 5 determined by HPLC, $98.8 \%$ ee (method 3) $\mathrm{mAU}$

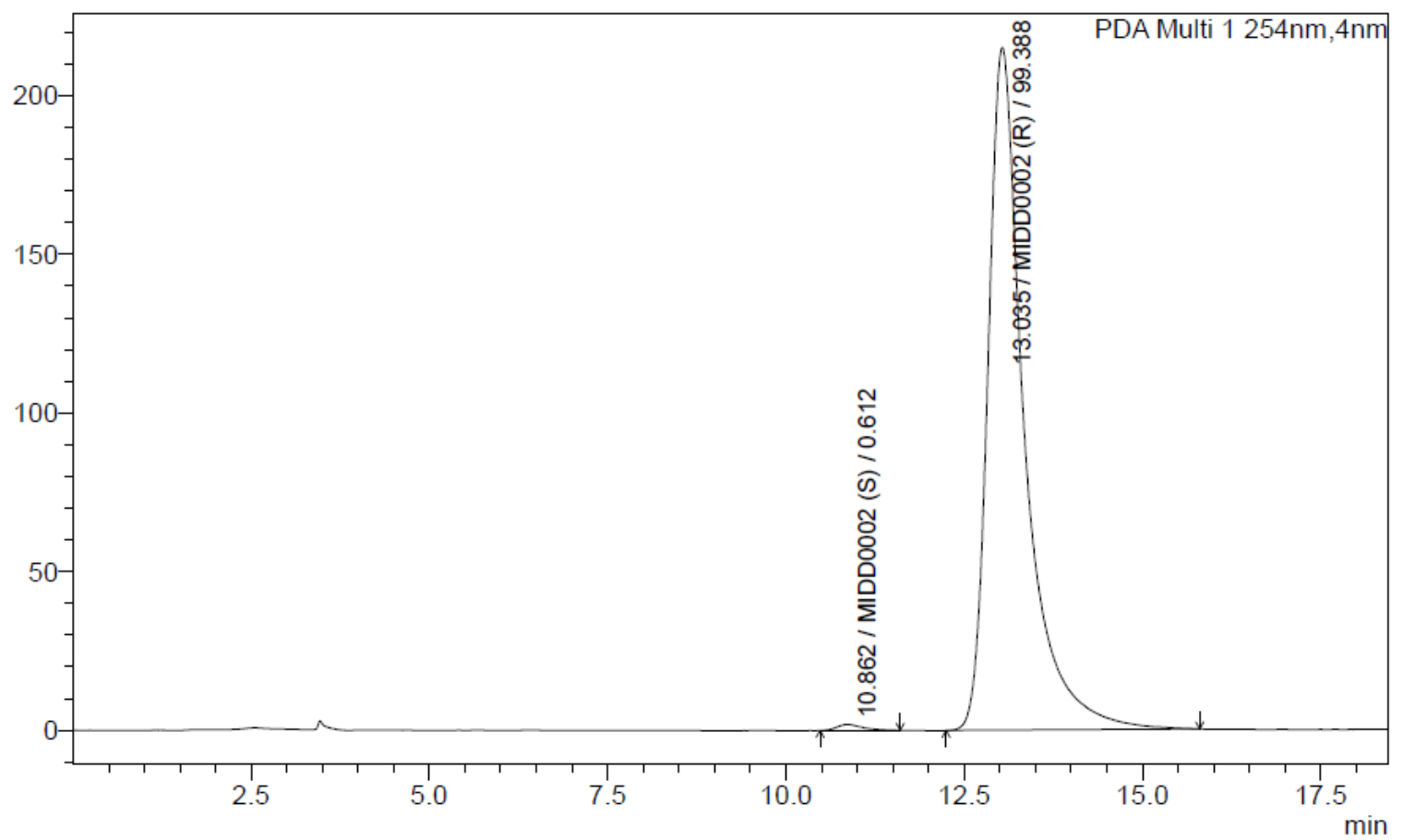


HPLC chromatogram $(245 \mathrm{~nm})$ for product $7(\operatorname{method} 1)$

mAU

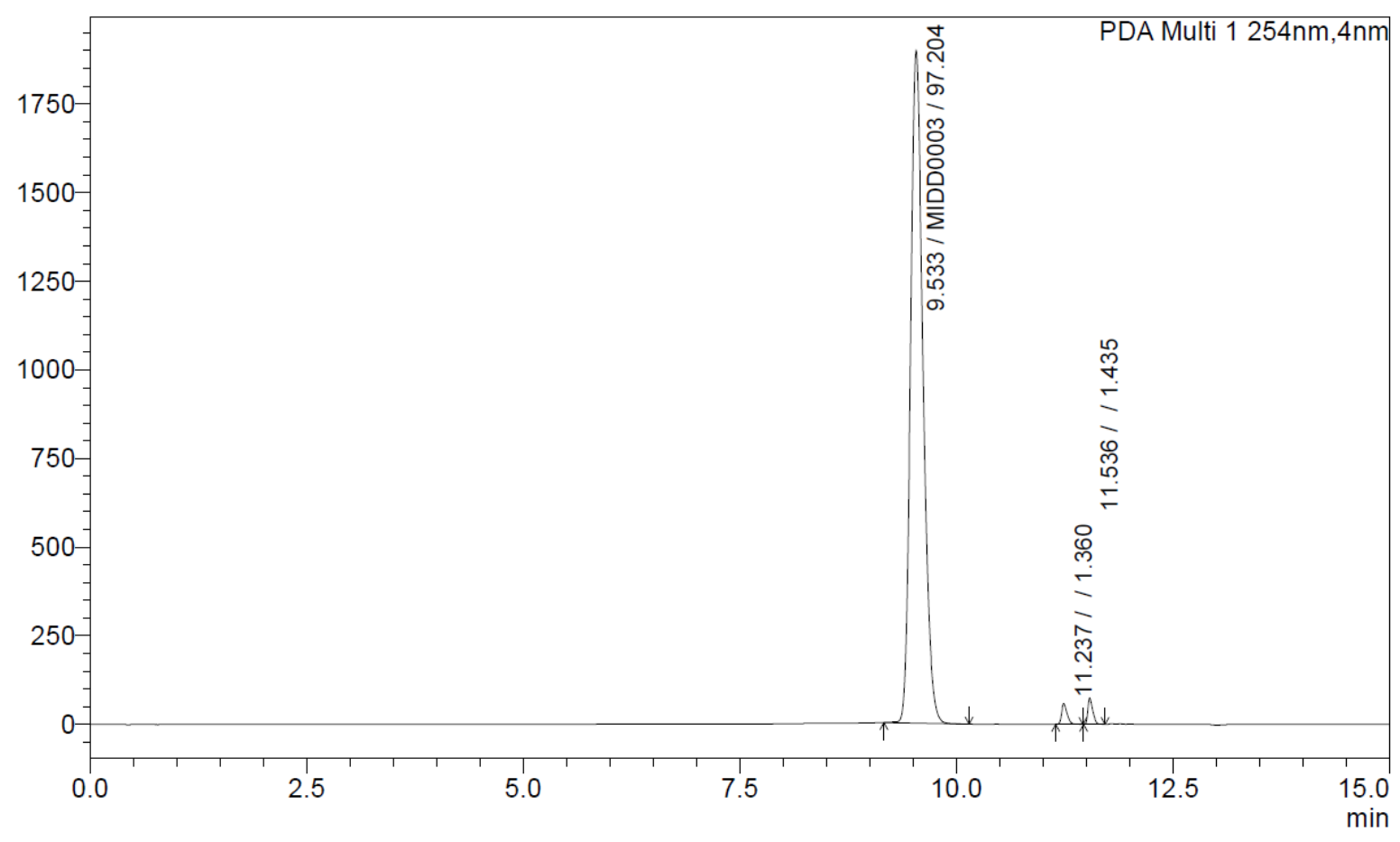

UV spectrum of 7 and impurities

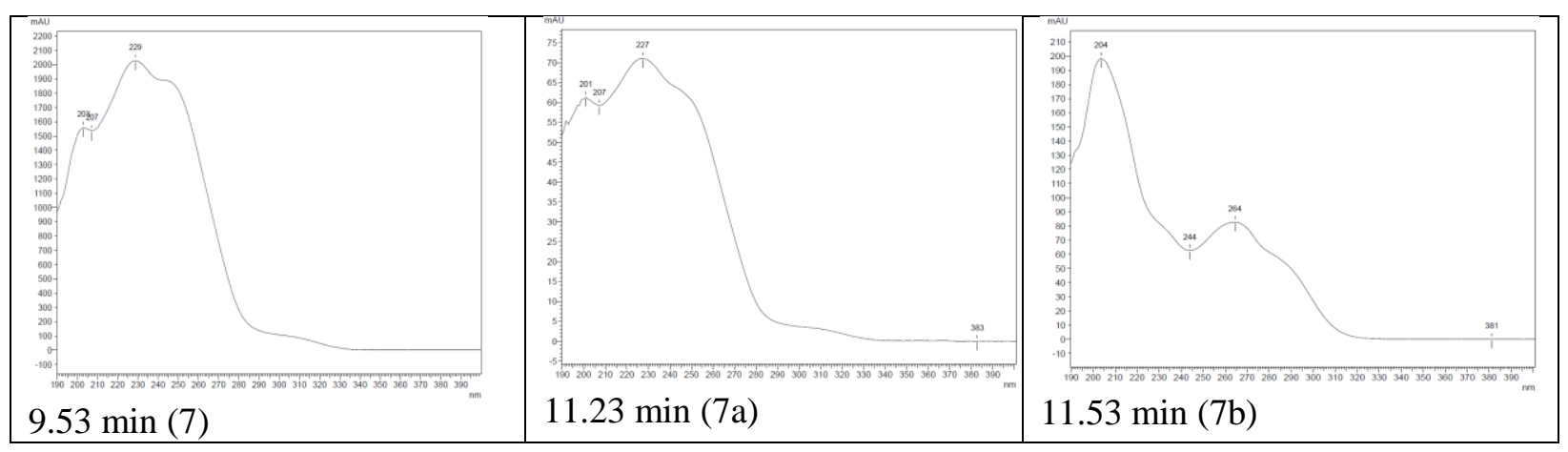


Mass spectrum of 7 (RT 9.55 min, method 1) (97.20\% absolute area)

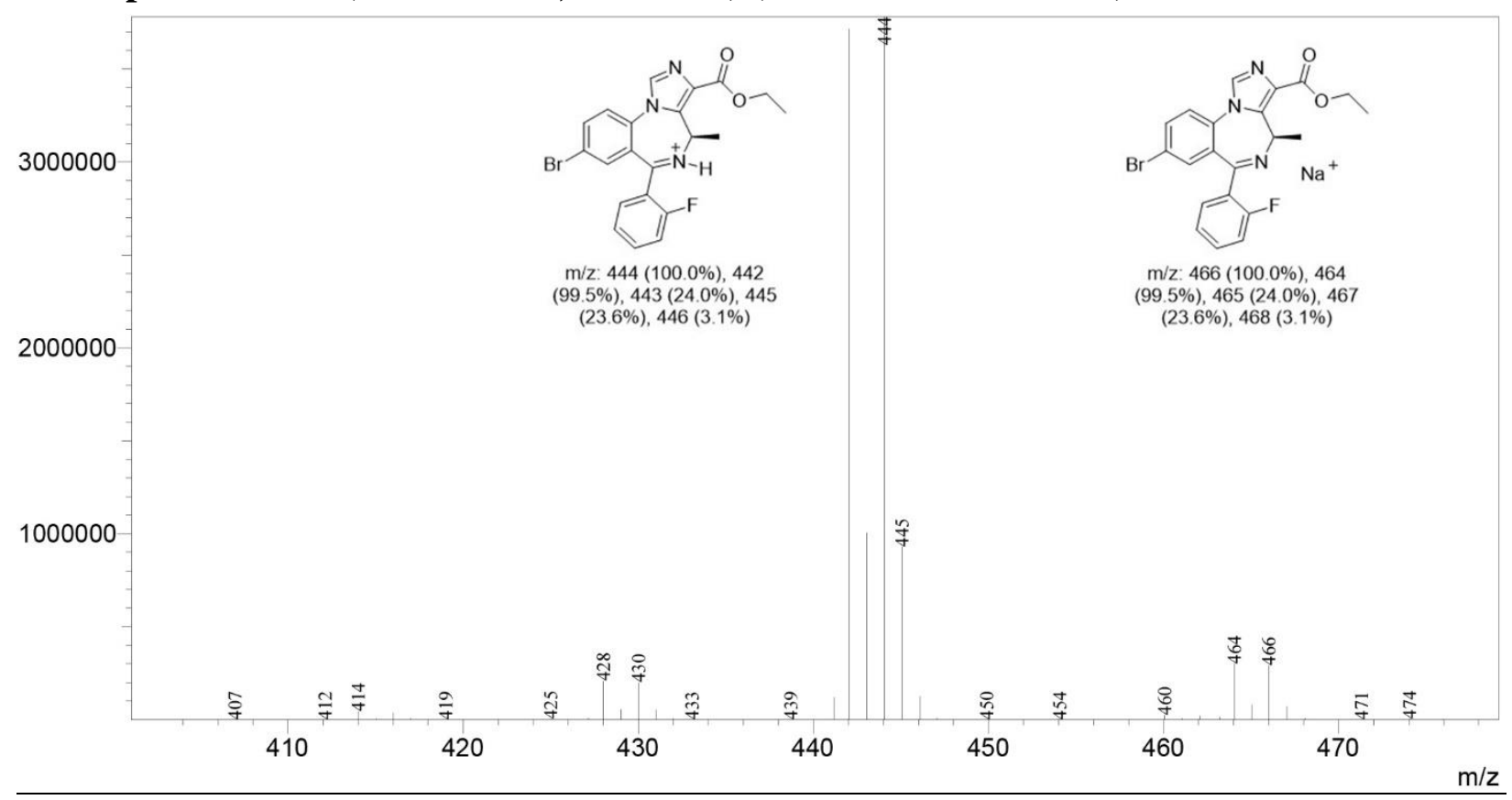

\section{Mass spectrum of 7a (RT $11.24 \mathrm{~min}$, method 1) (1.36\% absolute area)}

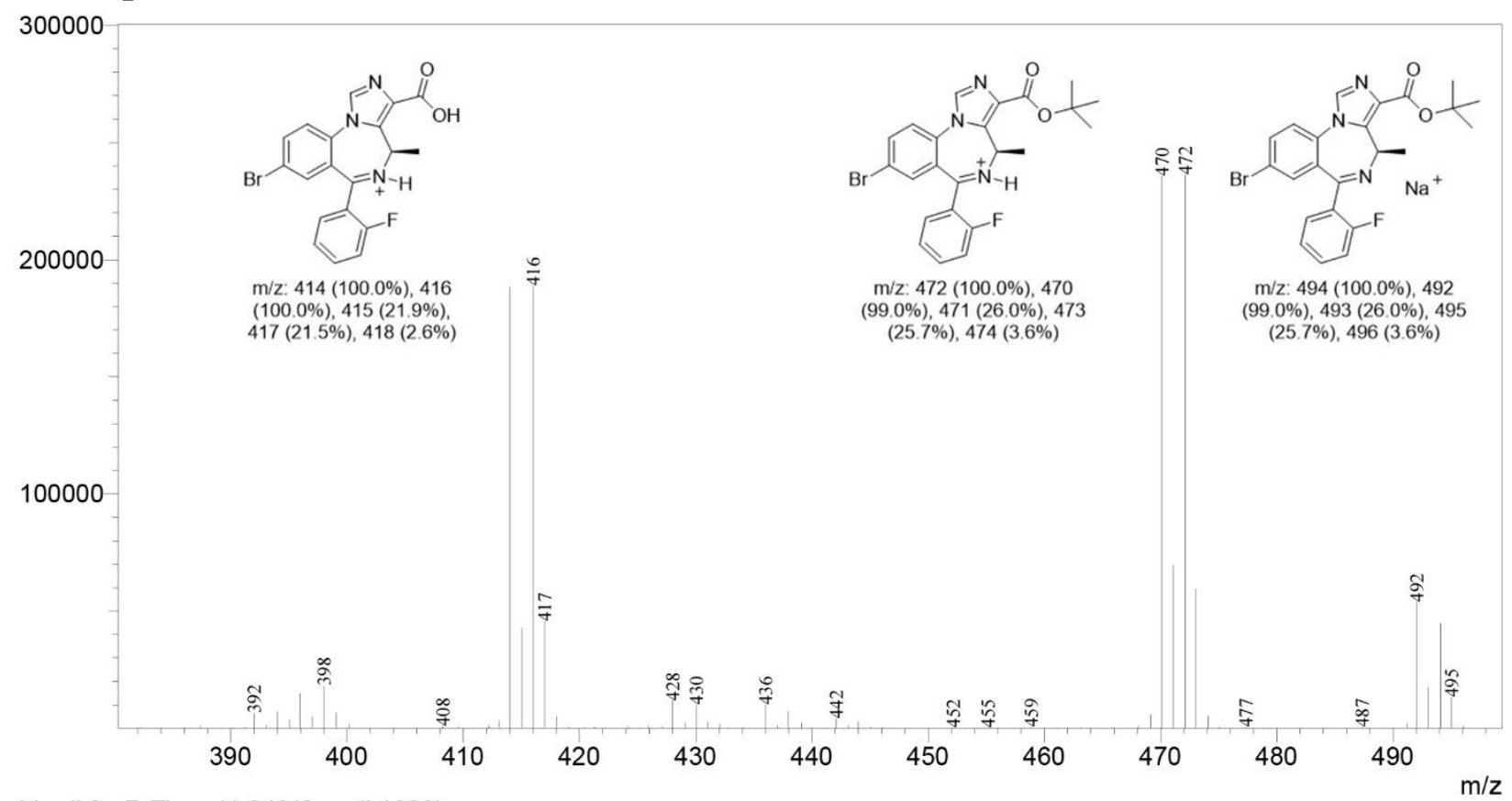


Mass spectrum of $7 \mathrm{~b}$ (RT $11.54 \mathrm{~min}$, method 1) (1.44\% absolute area)

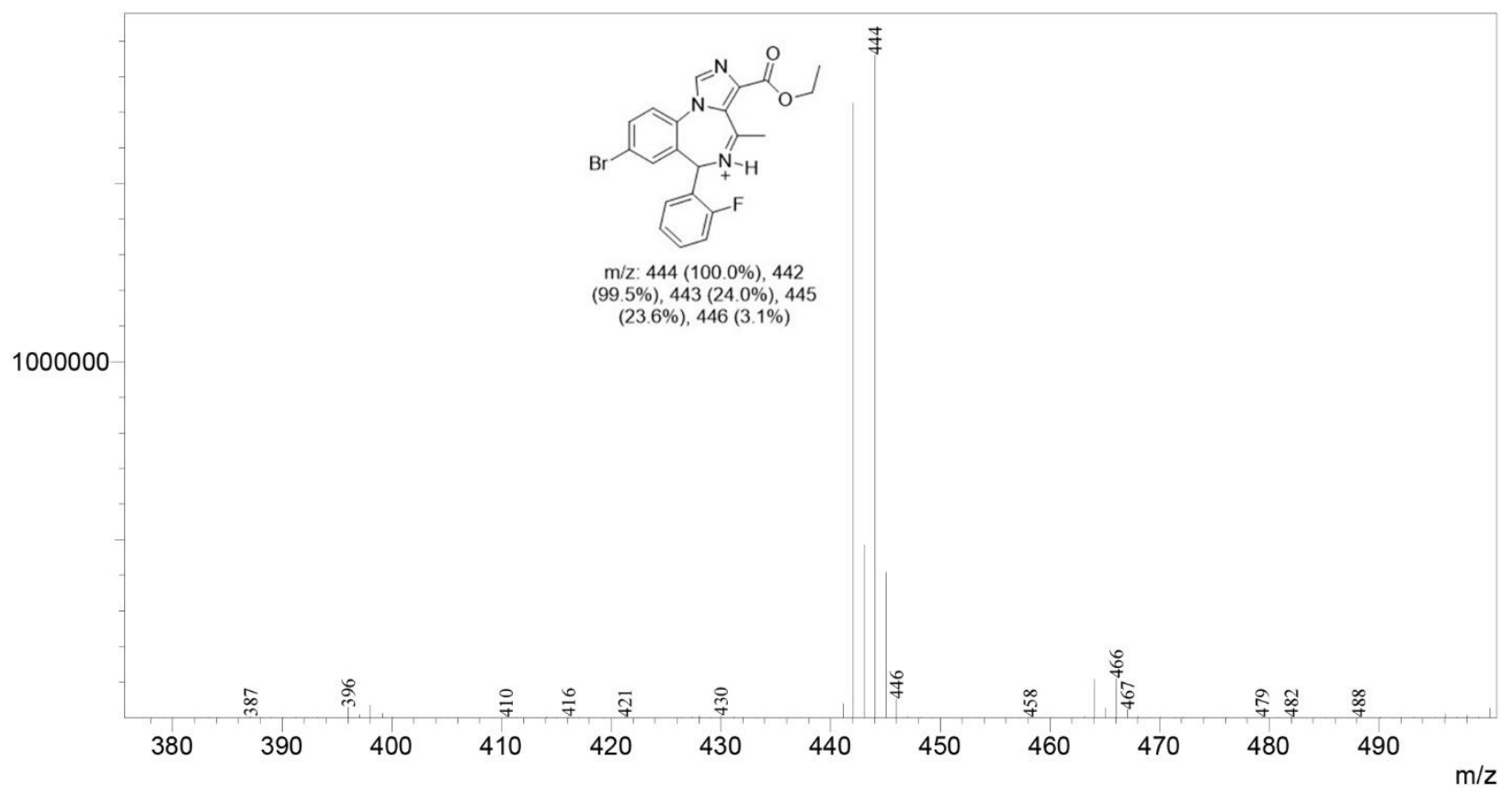

Optical purity of 7 determined by HPLC (Method 4) $99.0 \%$ ee mAU

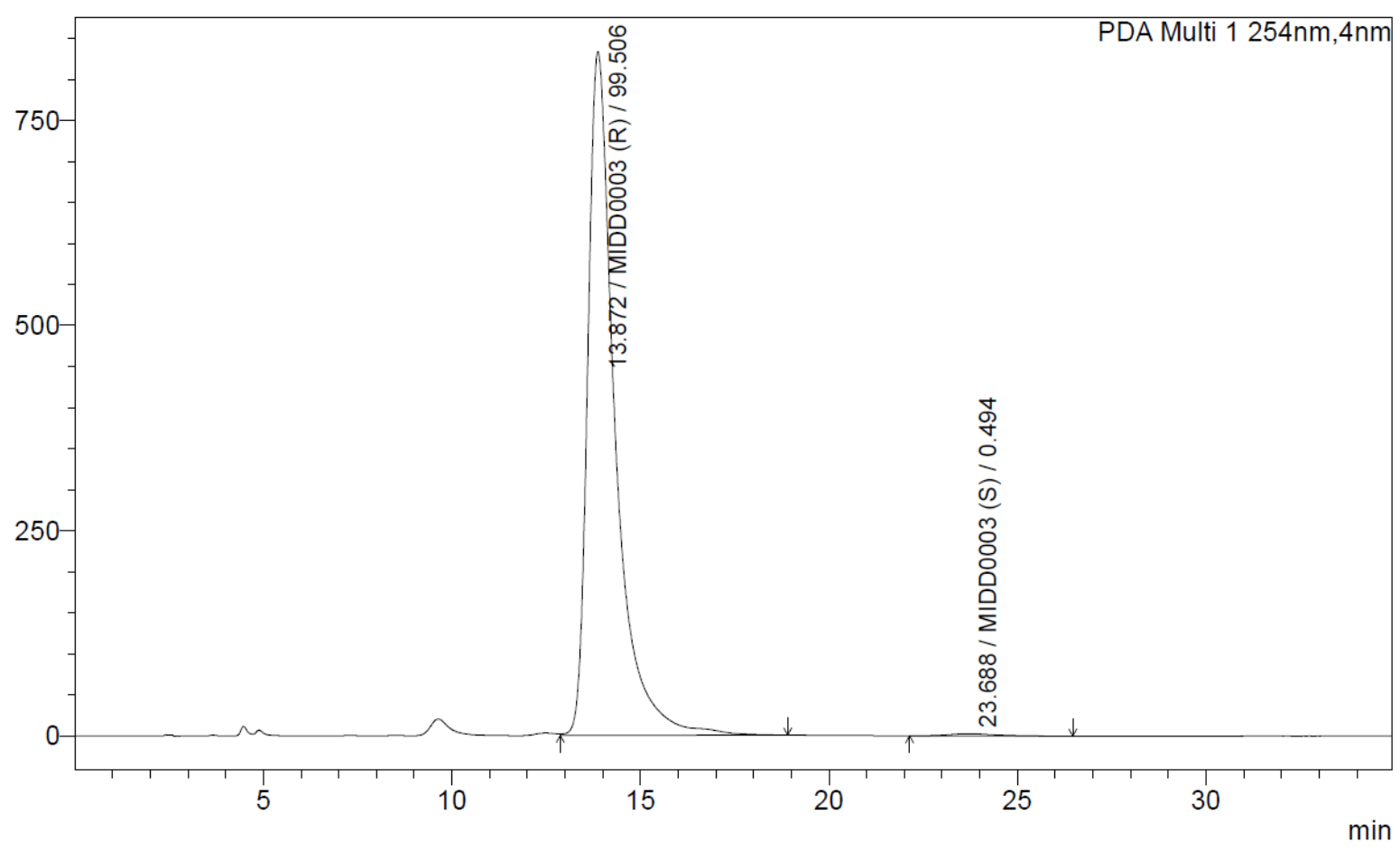


HPLC chromatogram (245 $\mathrm{nm})$ for product MIDD0301 (method 2)

mAU

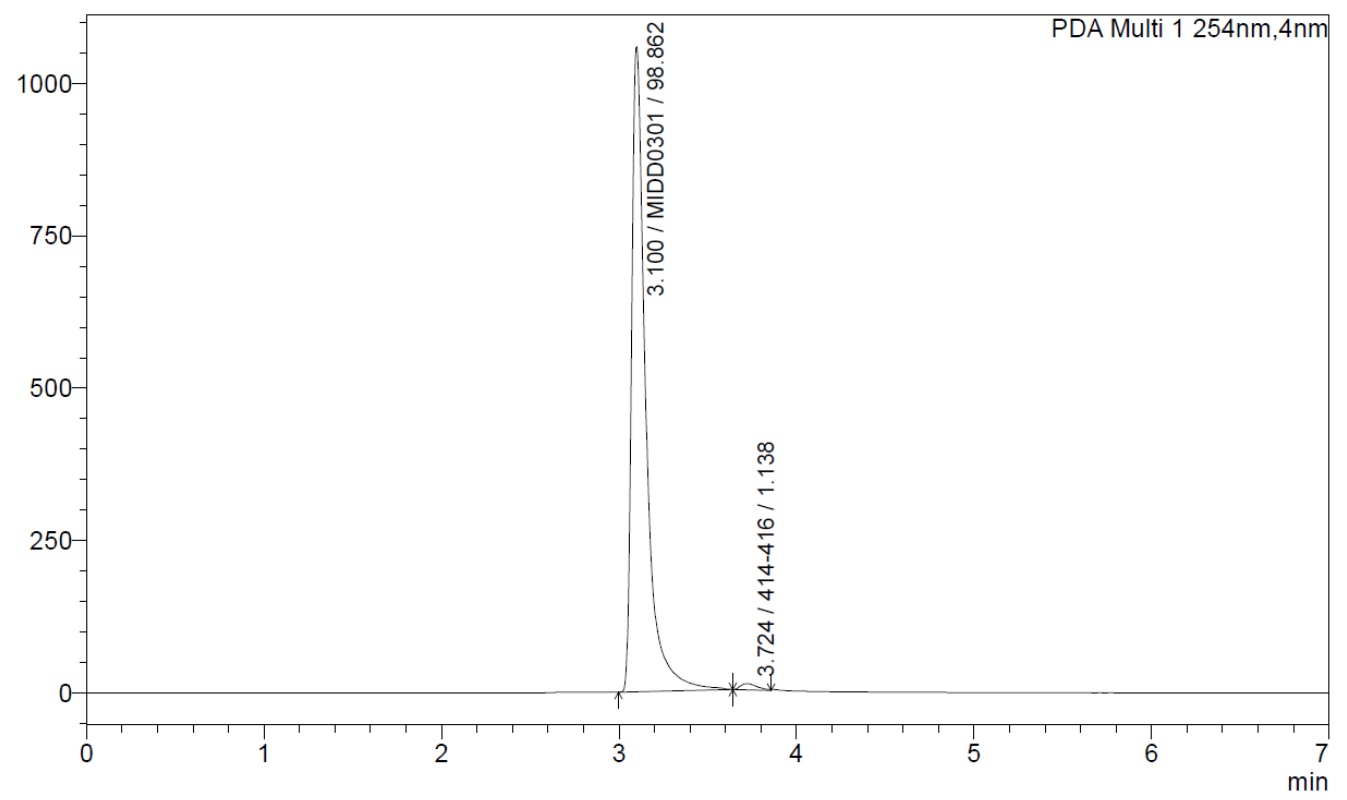

UV spectrum of MIDD0301 and impurities

\begin{tabular}{|l|l|l|}
\hline 3.10 MIDD 0301 & \\
\hline
\end{tabular}


Mass spectrum of MIDD0301 (RT 3.10 min, method 2) (98.86\% absolute area)

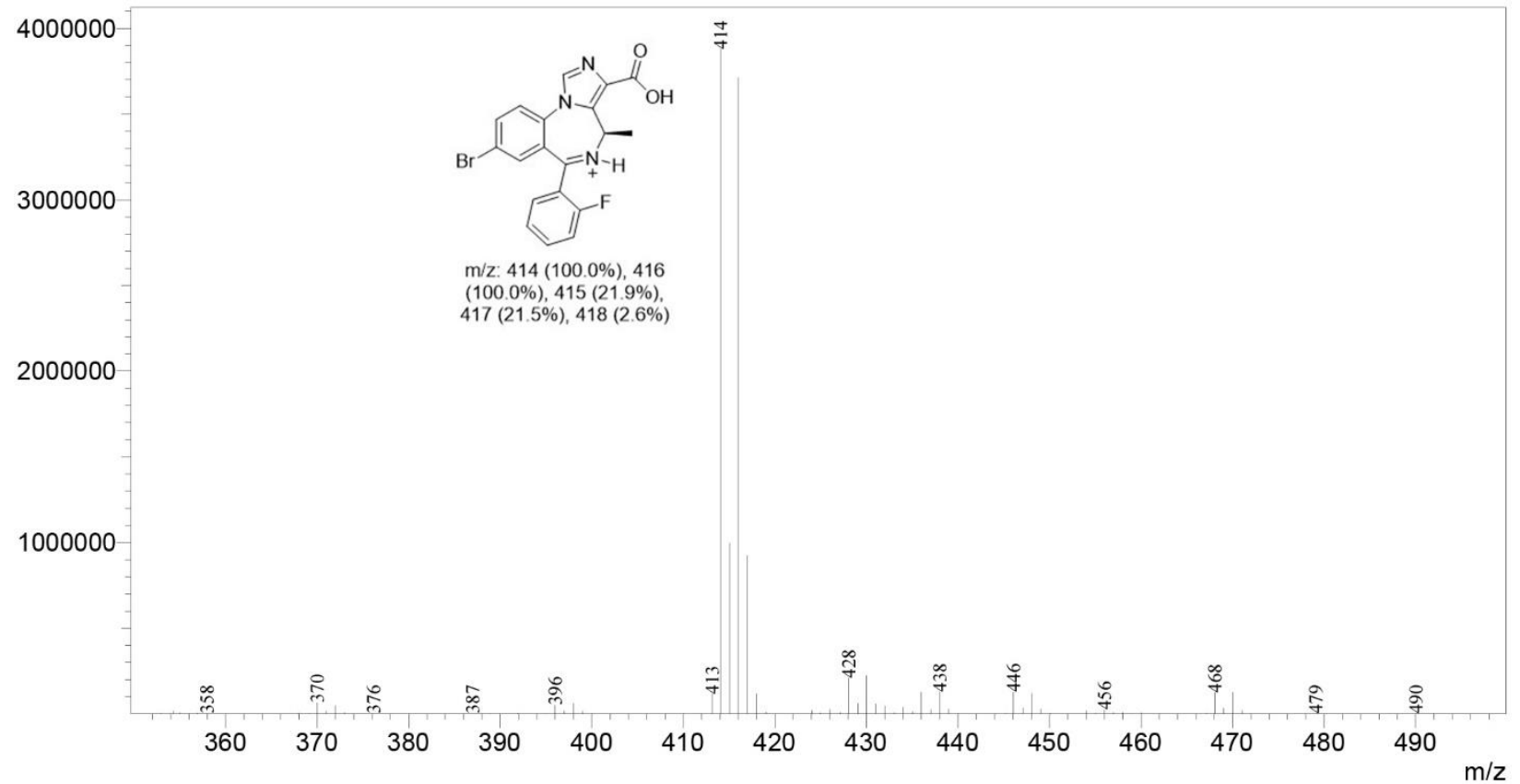

Mass spectrum MIDD0301a (RT 3.72 min, method 2) (1.14\% absolute area)

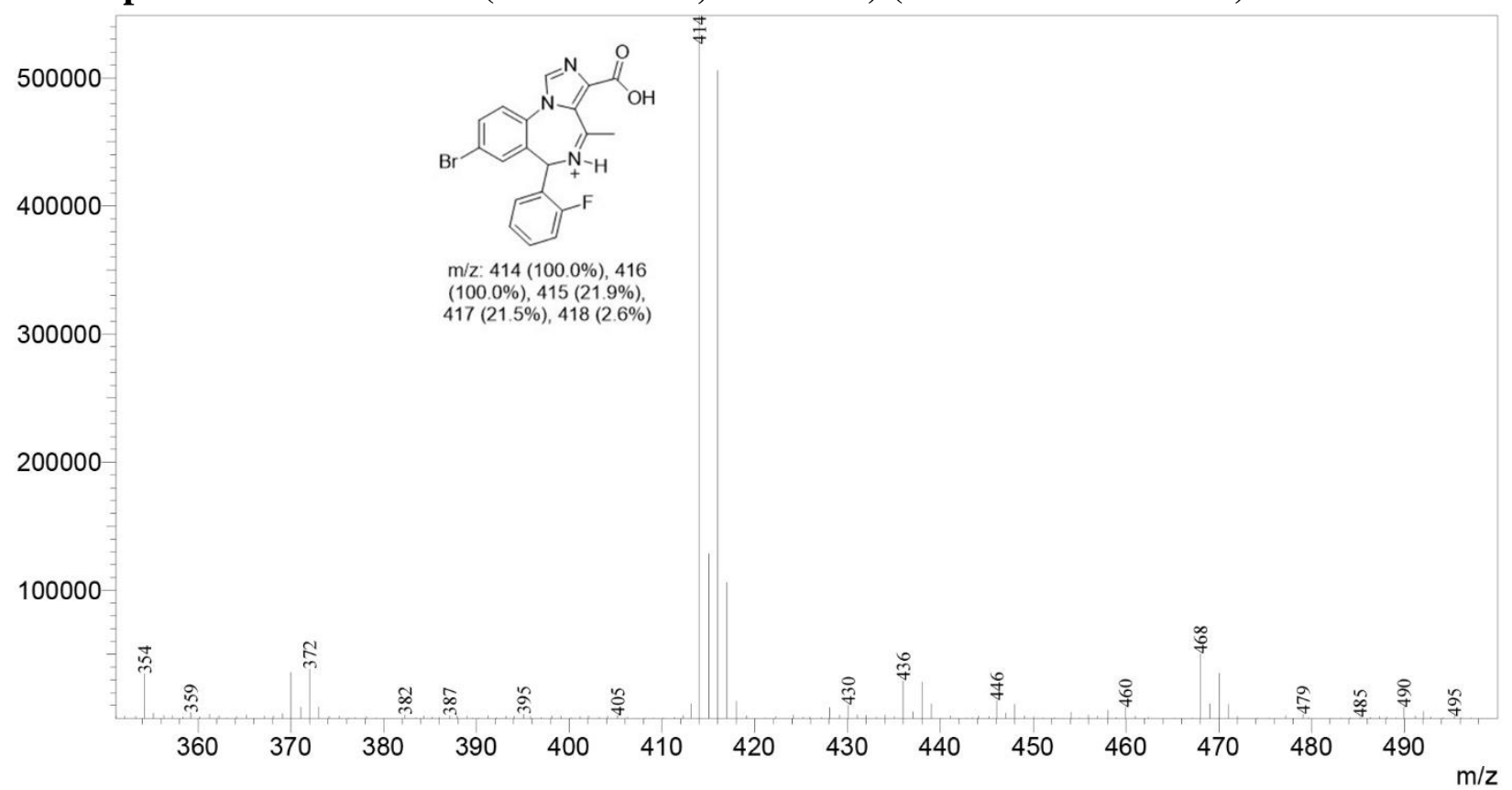


Optical purity of MIDD0301 determined by HPLC (Method 5) $>99.0 \%$ ee

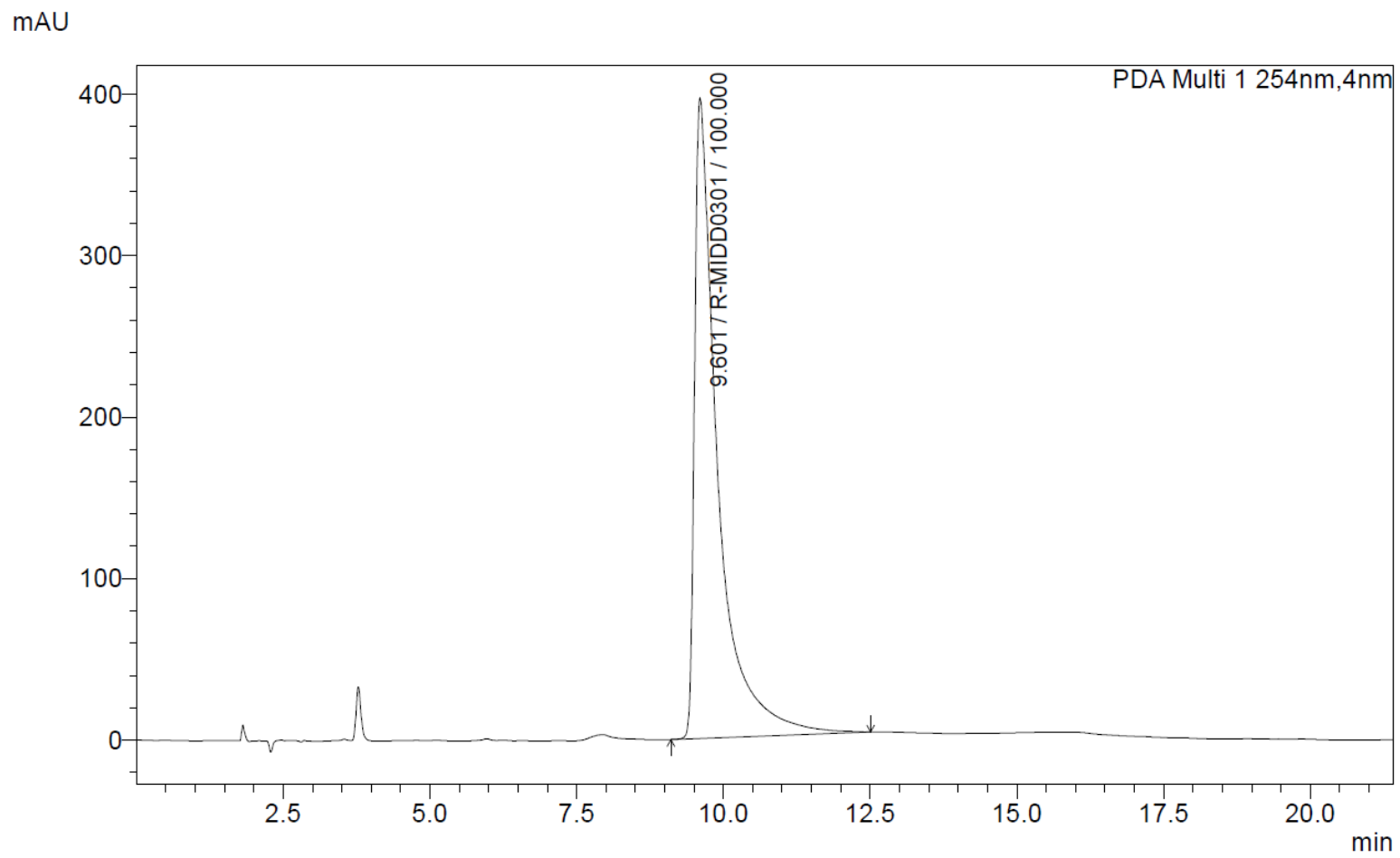




\section{${ }^{1}$ H NMR Spectra of 6}

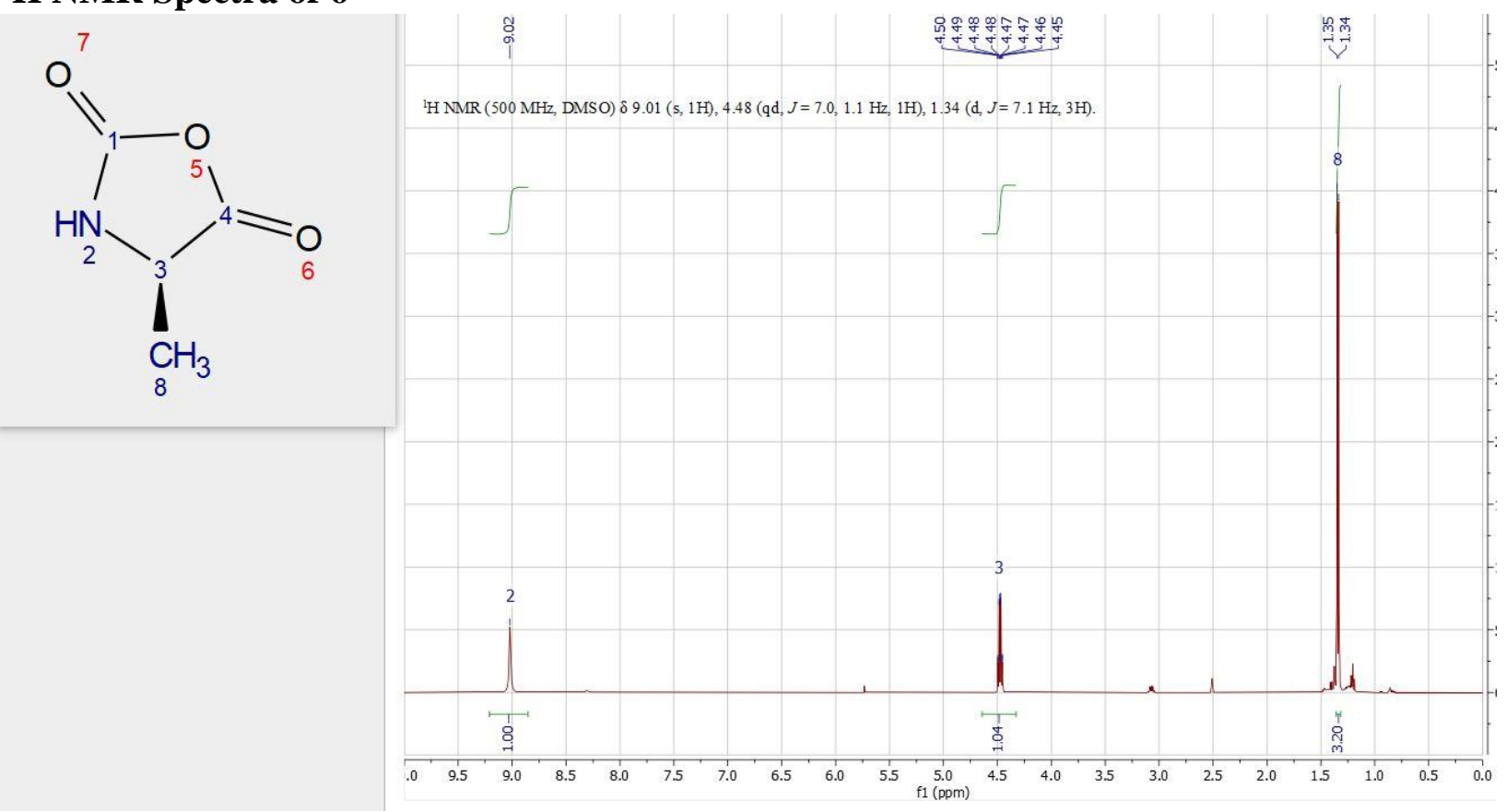

\section{${ }^{13}$ C NMR Spectra of 6}
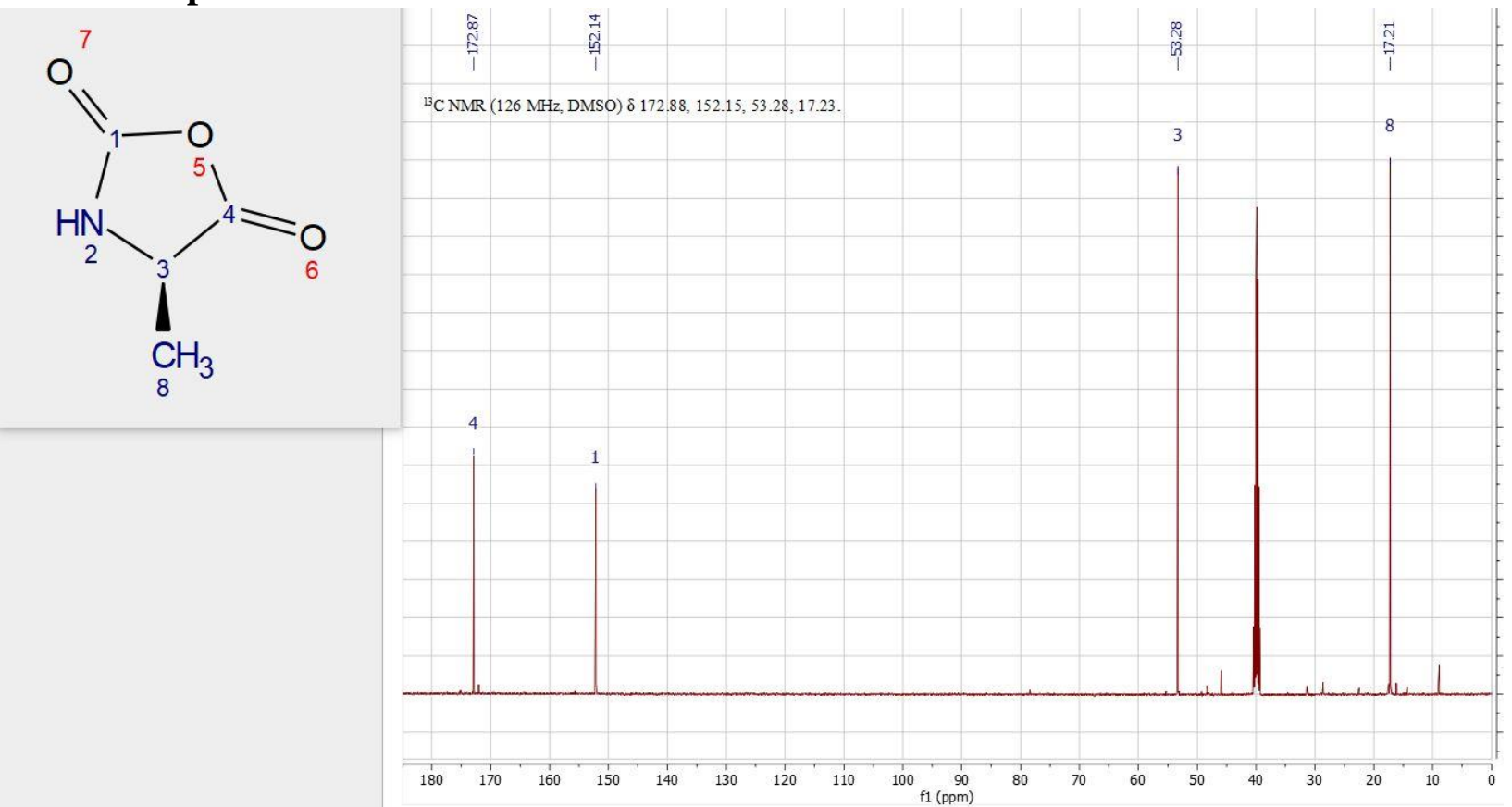


\section{COSY Spectra of 6}
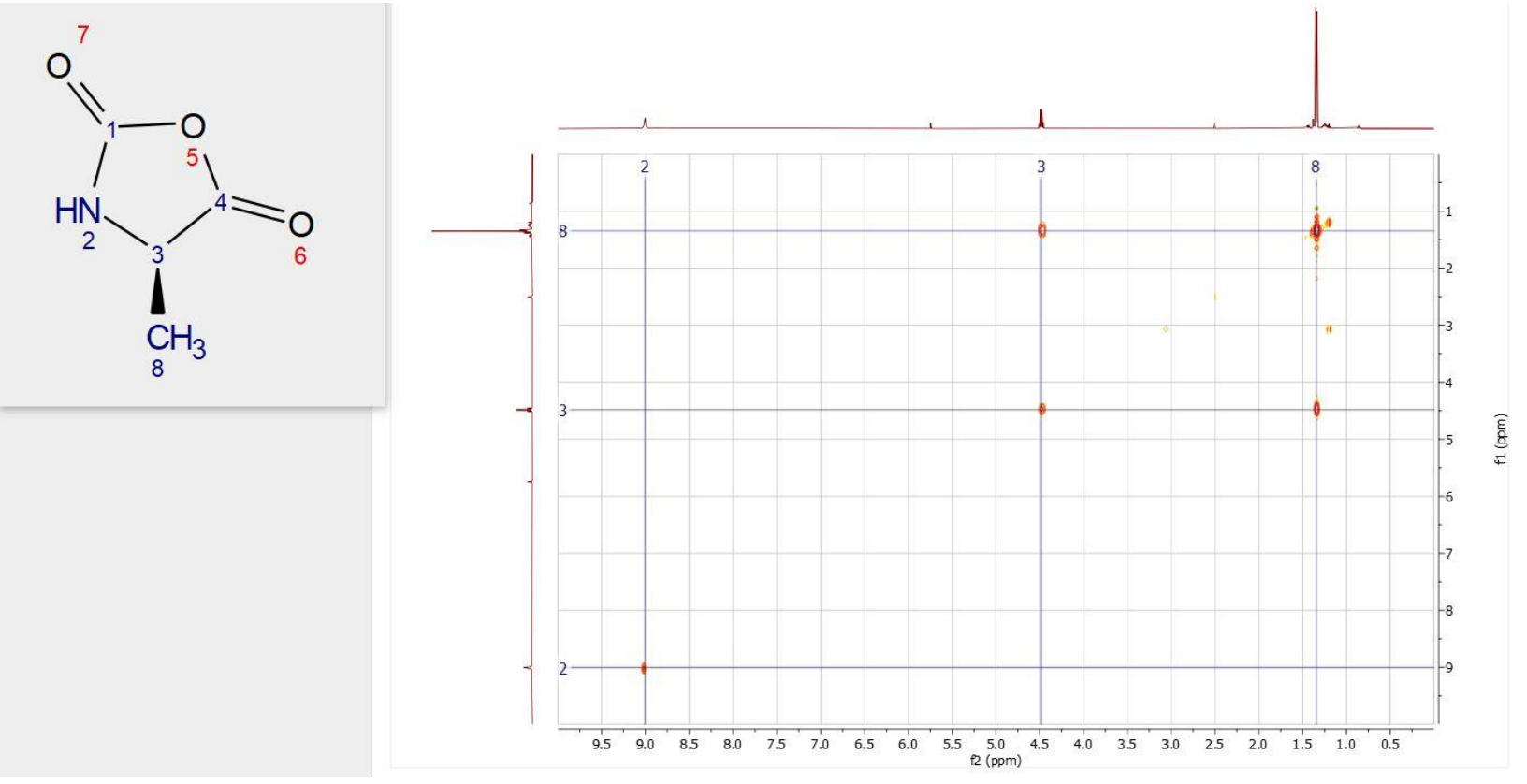

\section{${ }^{1} \mathrm{H}-{ }^{13} \mathrm{C}-\mathrm{HSQC}$ Spectra of 6}
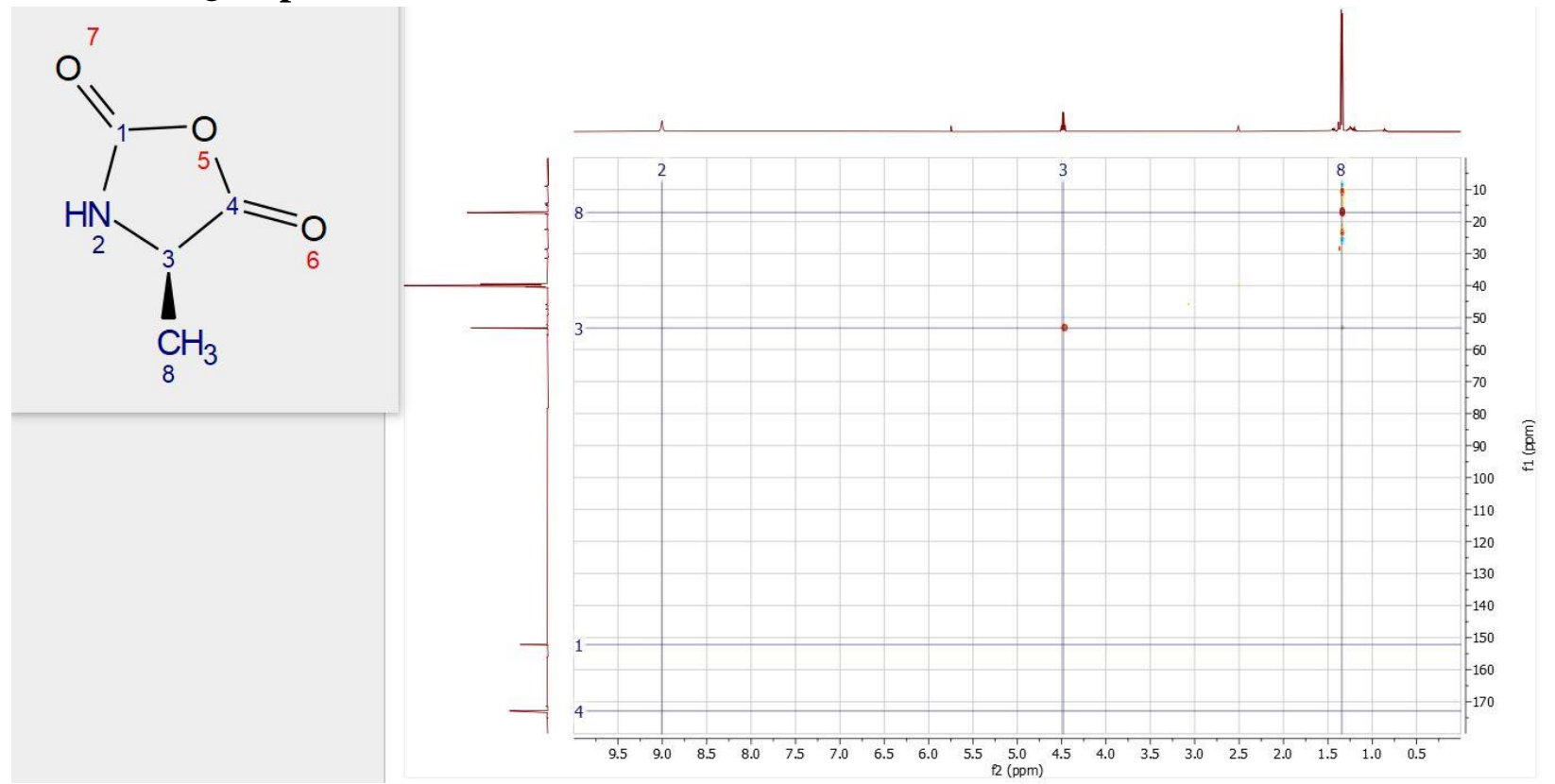
${ }^{1} \mathrm{H}-{ }^{13} \mathrm{C}-\mathrm{HMBC}$ Spectra of 6
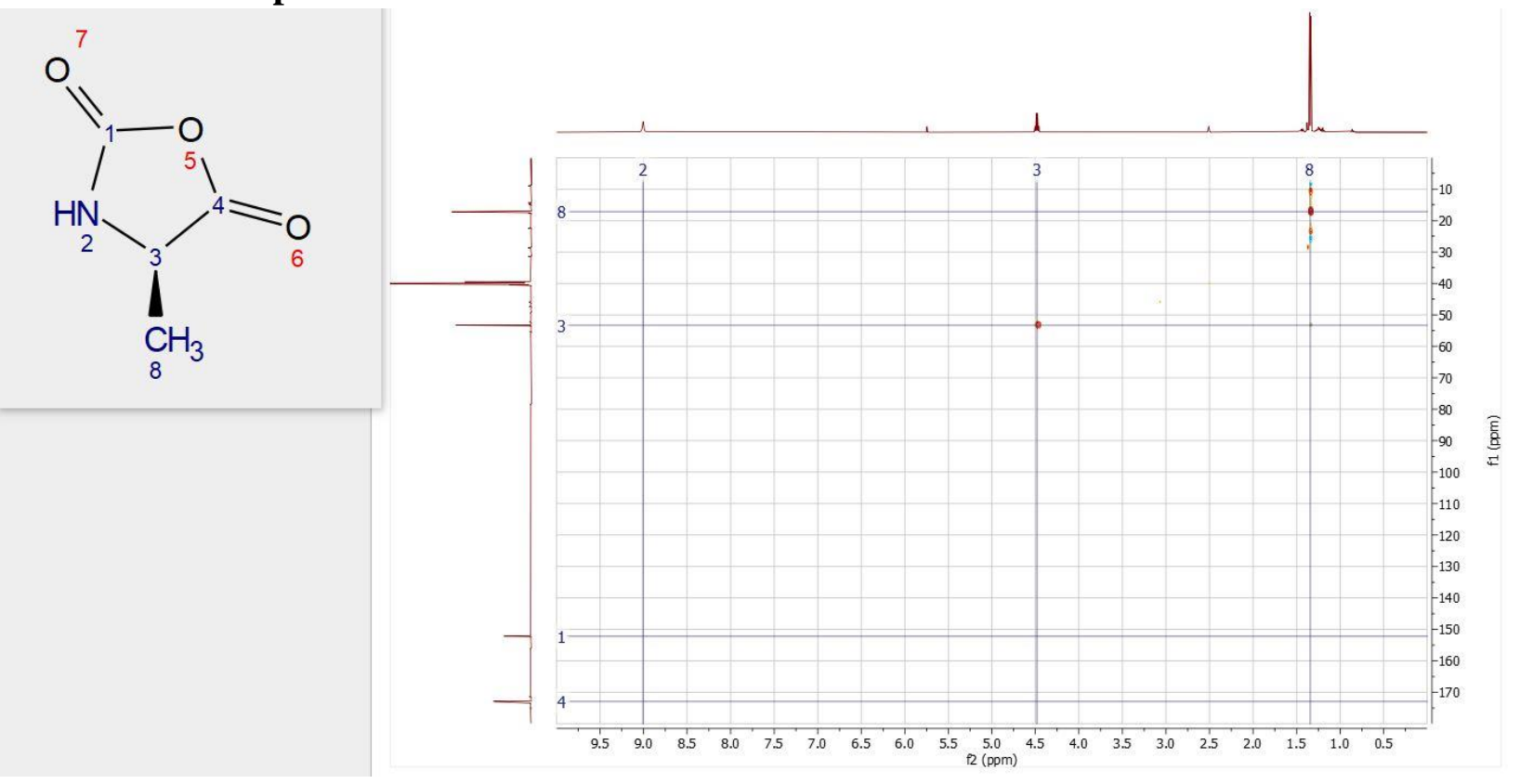


\section{${ }^{1} \mathrm{H}$ NMR Spectra of 5}<smiles>CC1N=C(n2nnnn2)c2cc(Br)ccc2NC1=O</smiles>

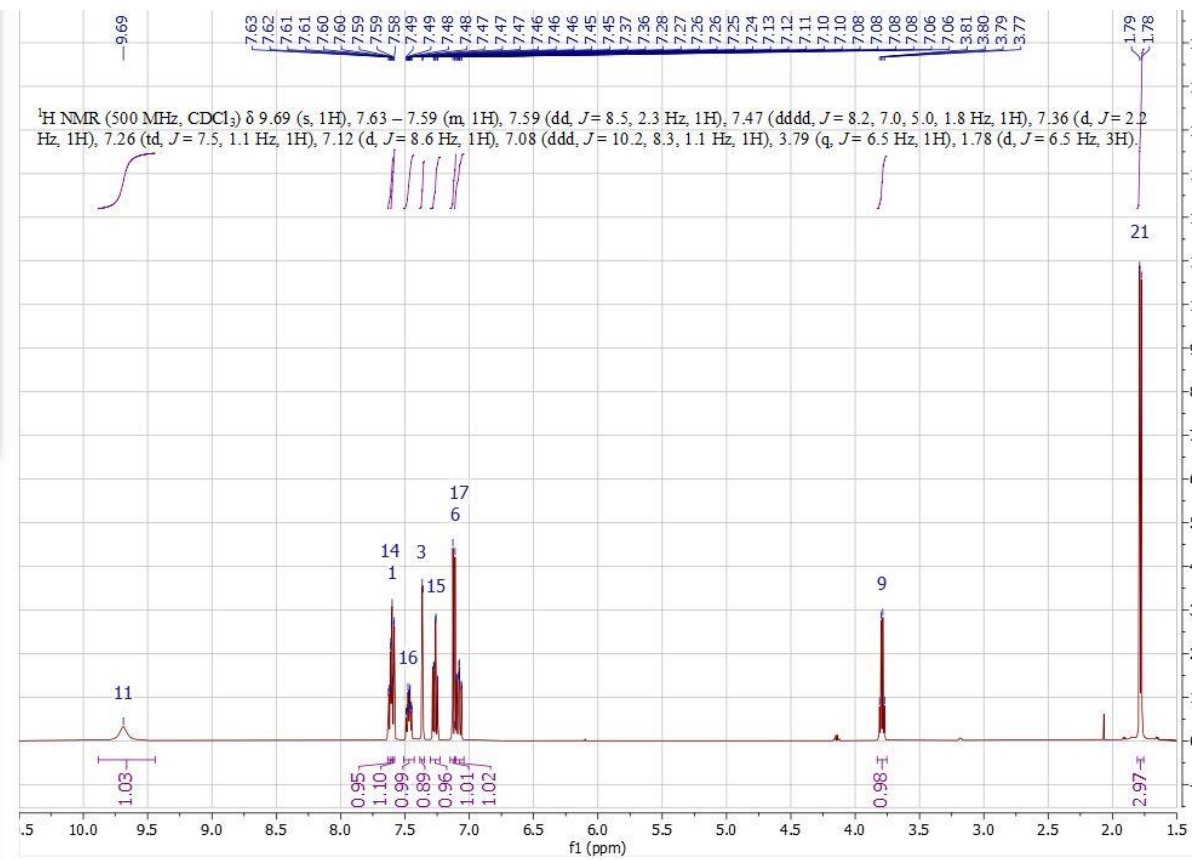

\section{${ }^{13}$ C NMR Spectra of 5}

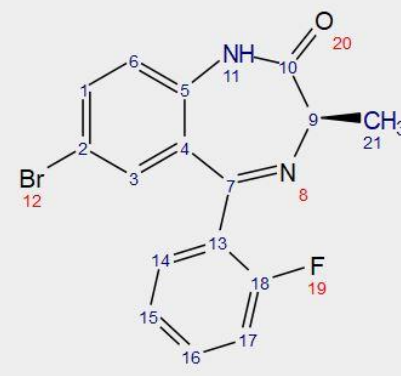

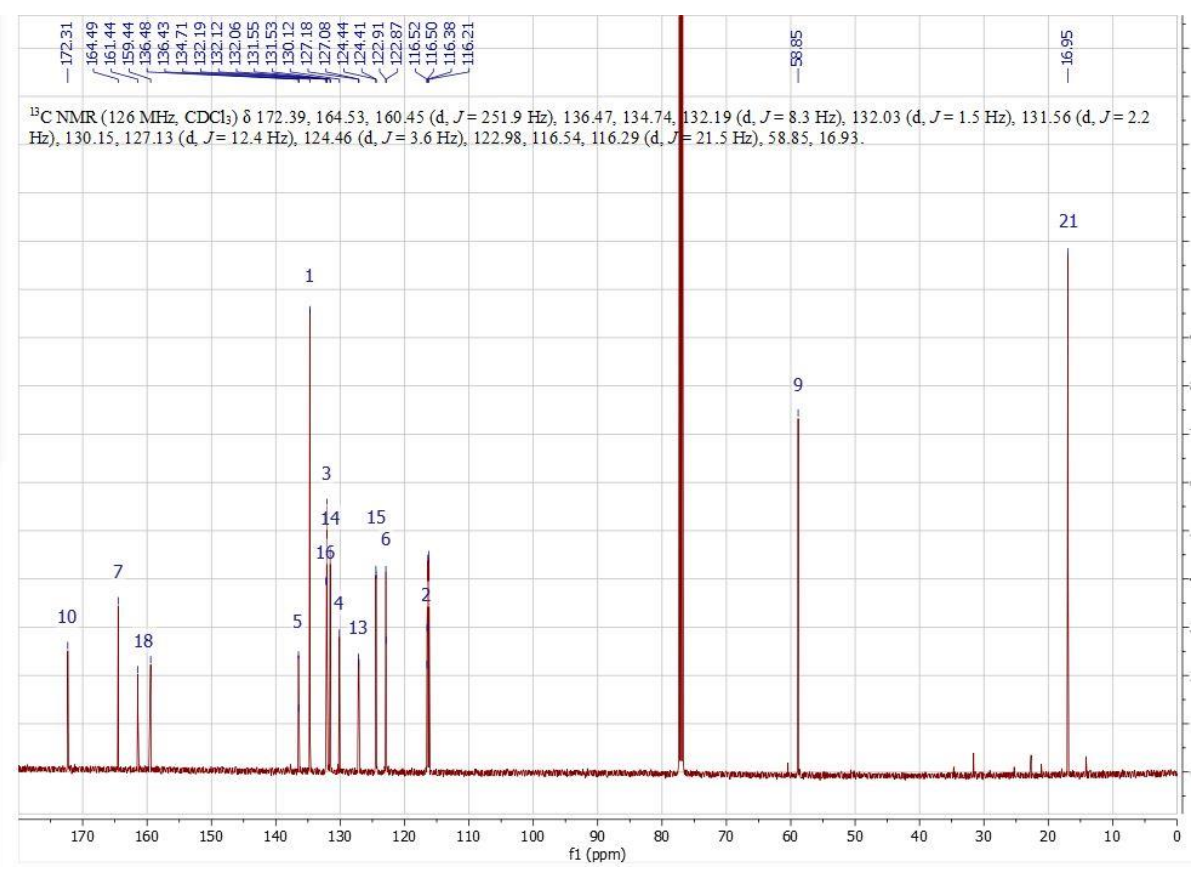




\section{COSY Spectra of 5}
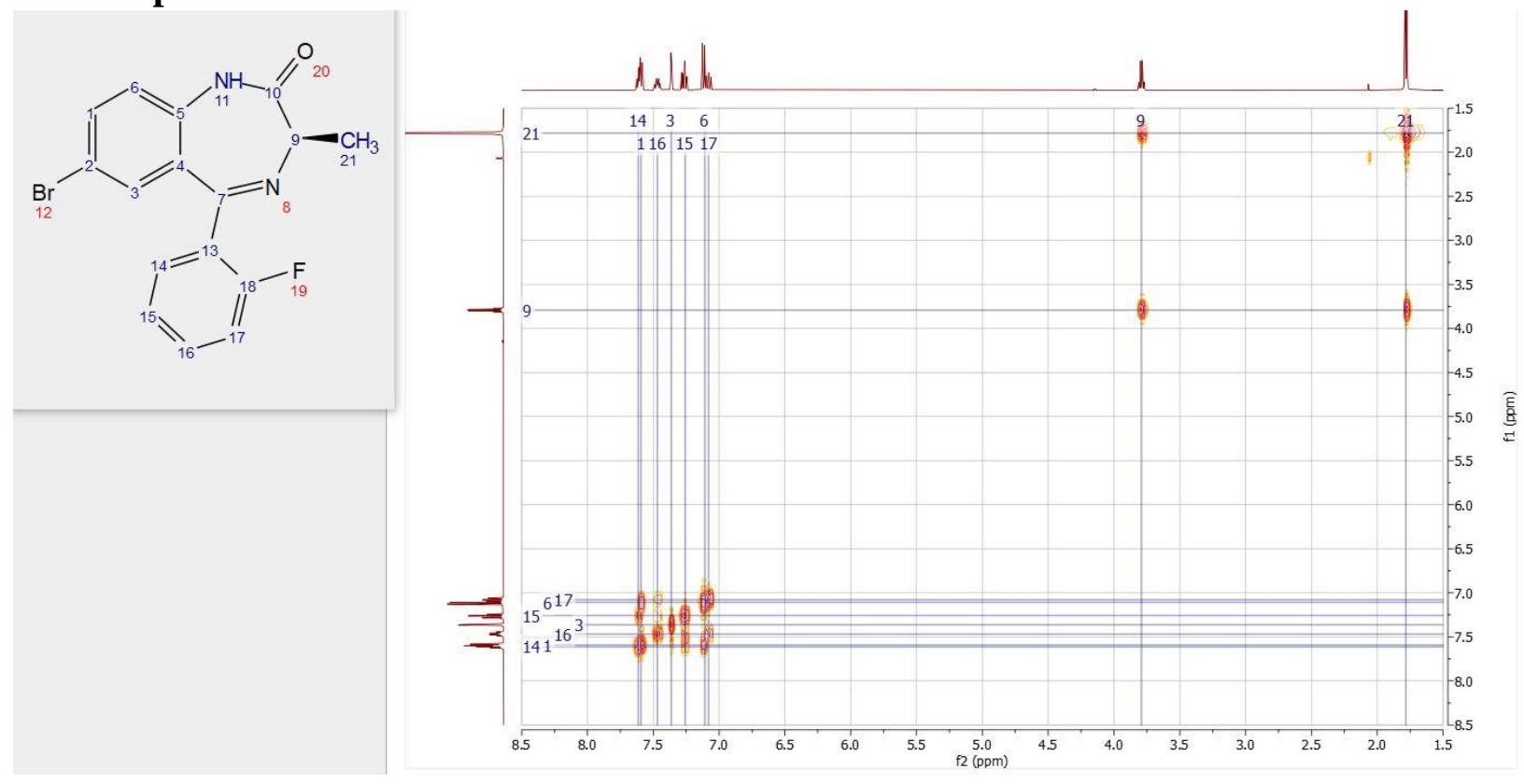

\section{${ }^{1} \mathrm{H}-{ }^{13} \mathrm{C}-H S Q C$ Spectra of 5}
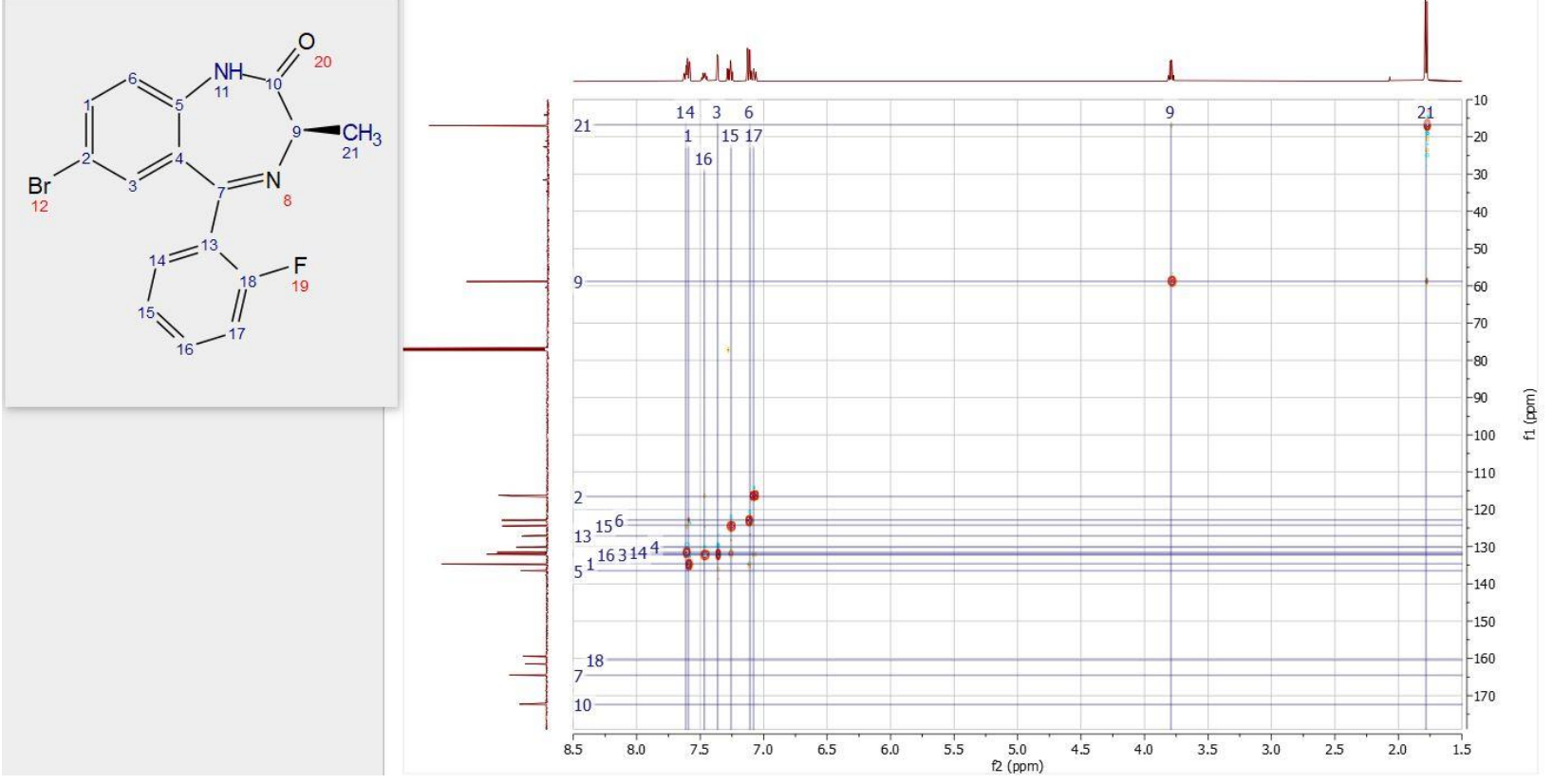


\section{${ }^{1} \mathrm{H}-{ }^{13} \mathrm{C}-\mathrm{HMBC}$ Spectra of 5}
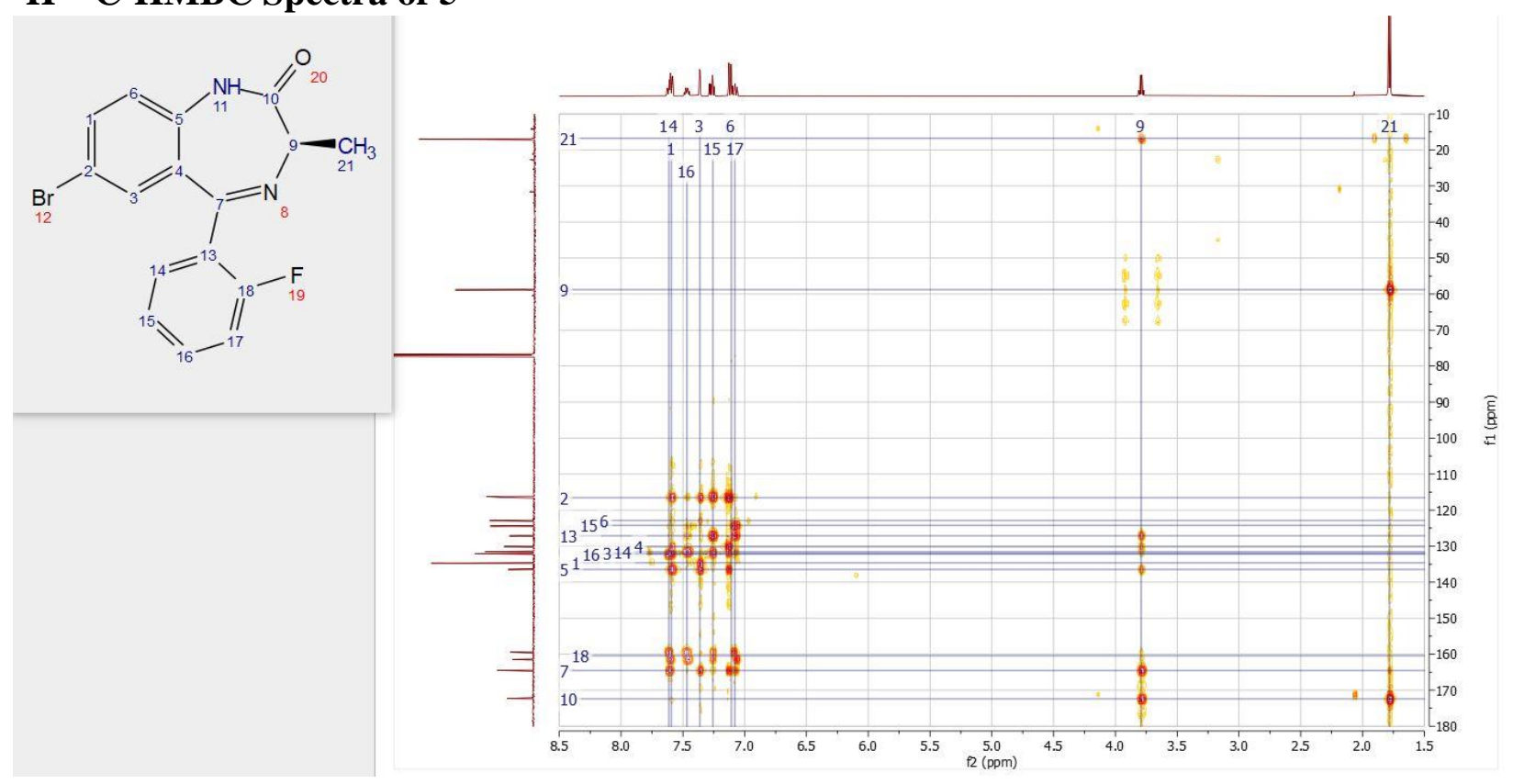


\section{${ }^{1} \mathrm{H}$ NMR Spectra of 7}<smiles>CCO[PH](=O)C1=NCN2c3ccc(Br)cc3C(n3cnnn3)=NC(C)N12</smiles>

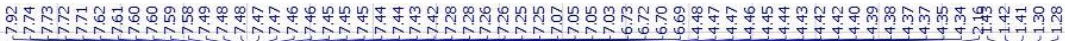

${ }^{1} \mathrm{H} \mathrm{NMR}\left(500 \mathrm{MHz}, \mathrm{CDCl}_{3}\right) \delta 7.92(\mathrm{~s}, 1 \mathrm{H}), 7.73$ (dd, $\left.J=8.5,2.2 \mathrm{~Hz}, 1 \mathrm{H}\right), 7.60$ (dt, $\left.J=7.3,3.9 \mathrm{~Hz}, 1 \mathrm{H}\right), 7.48(\mathrm{~d}, J=8.6 \mathrm{~Hz}$ $1 \mathrm{H}), 7.50-7.42(\mathrm{~m}, 1 \mathrm{H}), 7.42(\mathrm{~d}, J=2.2 \mathrm{~Hz}, 1 \mathrm{H}), 7.26(\mathrm{td}, J=7.5,1.1 \mathrm{~Hz}, 1 \mathrm{H}), 7.10-7.02(\mathrm{~m}, 1 \mathrm{H}), 6.71(\mathrm{q}, J=7.3 \mathrm{~Hz}$

$1 \mathrm{H}), 4.54-4.28(\mathrm{~m}, 2 \mathrm{H}), 1.42(\mathrm{t}, J=7.1 \mathrm{~Hz}, 3 \mathrm{H}), 1.29(\mathrm{~d}, J=7.4 \mathrm{~Hz}, 3 \mathrm{H})$

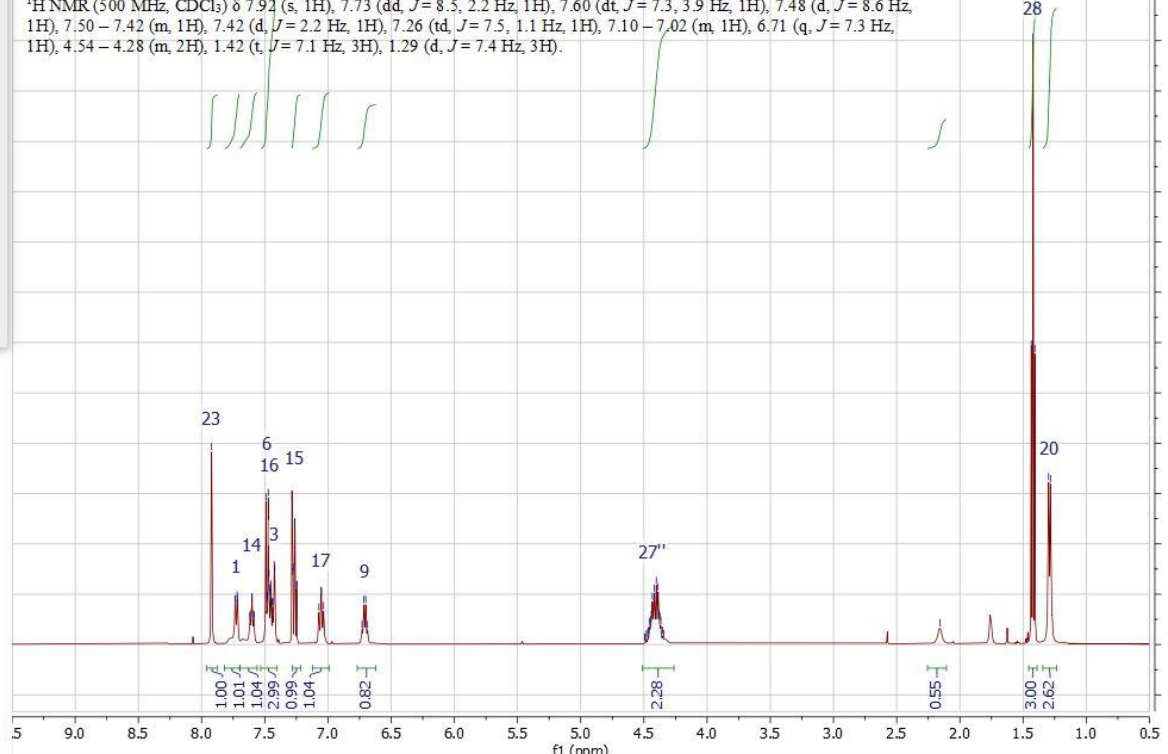

\section{${ }^{13}$ C NMR Spectra of 7}
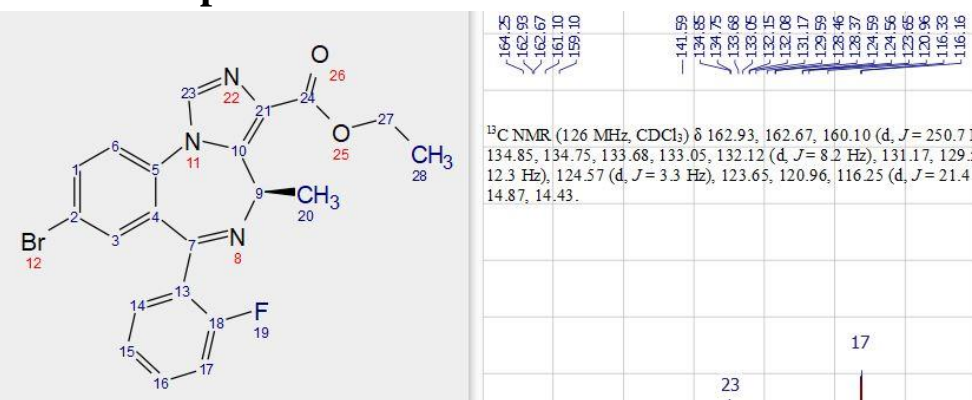

${ }^{13} \mathrm{C} \mathrm{NMR}\left(126 \mathrm{MHz}, \mathrm{CDCl}_{3}\right) \delta 162.93,162.67,160.10$ (d, $\left.J=250.7 \mathrm{~Hz}\right), 141.59$,

$134.85,134.75,133.68,133.05,132.12(\mathrm{~d}, J=82 \mathrm{~Hz}), 131.17,129.59,128.42(\mathrm{~d}, J=$

$12.3 \mathrm{~Hz}), 124.57(\mathrm{~d}, J=3.3 \mathrm{~Hz}), 123.65,120.96,116.25(\mathrm{~d}, J=21.4 \mathrm{~Hz}), 60.82,50.12$,

$14.87,14.43$.
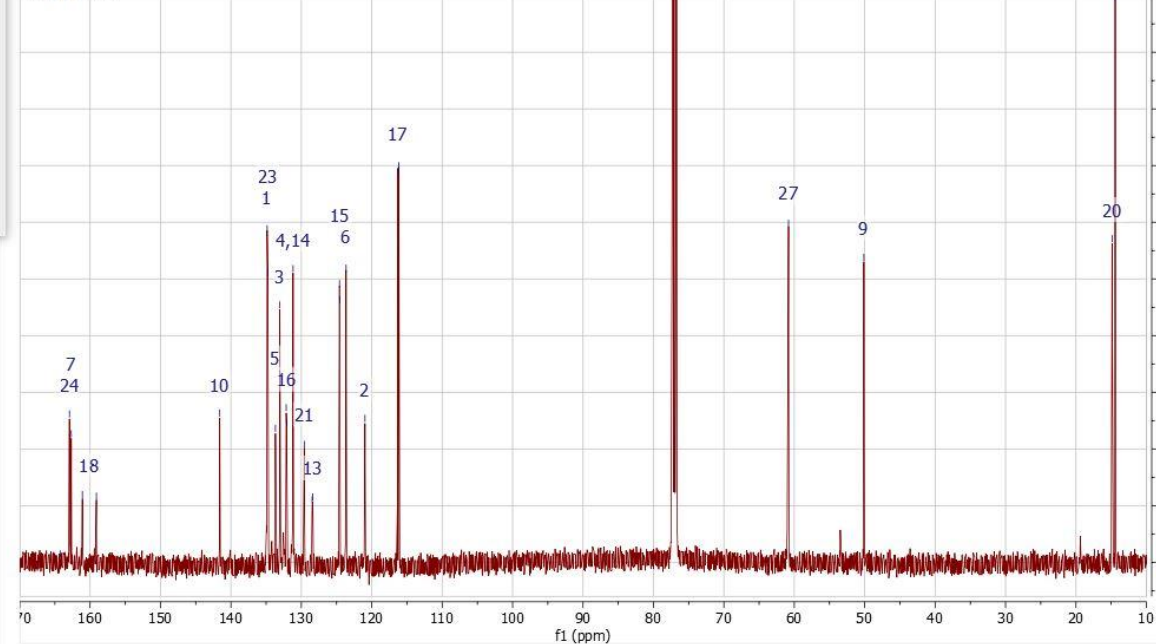


\section{COSY Spectra of 7}

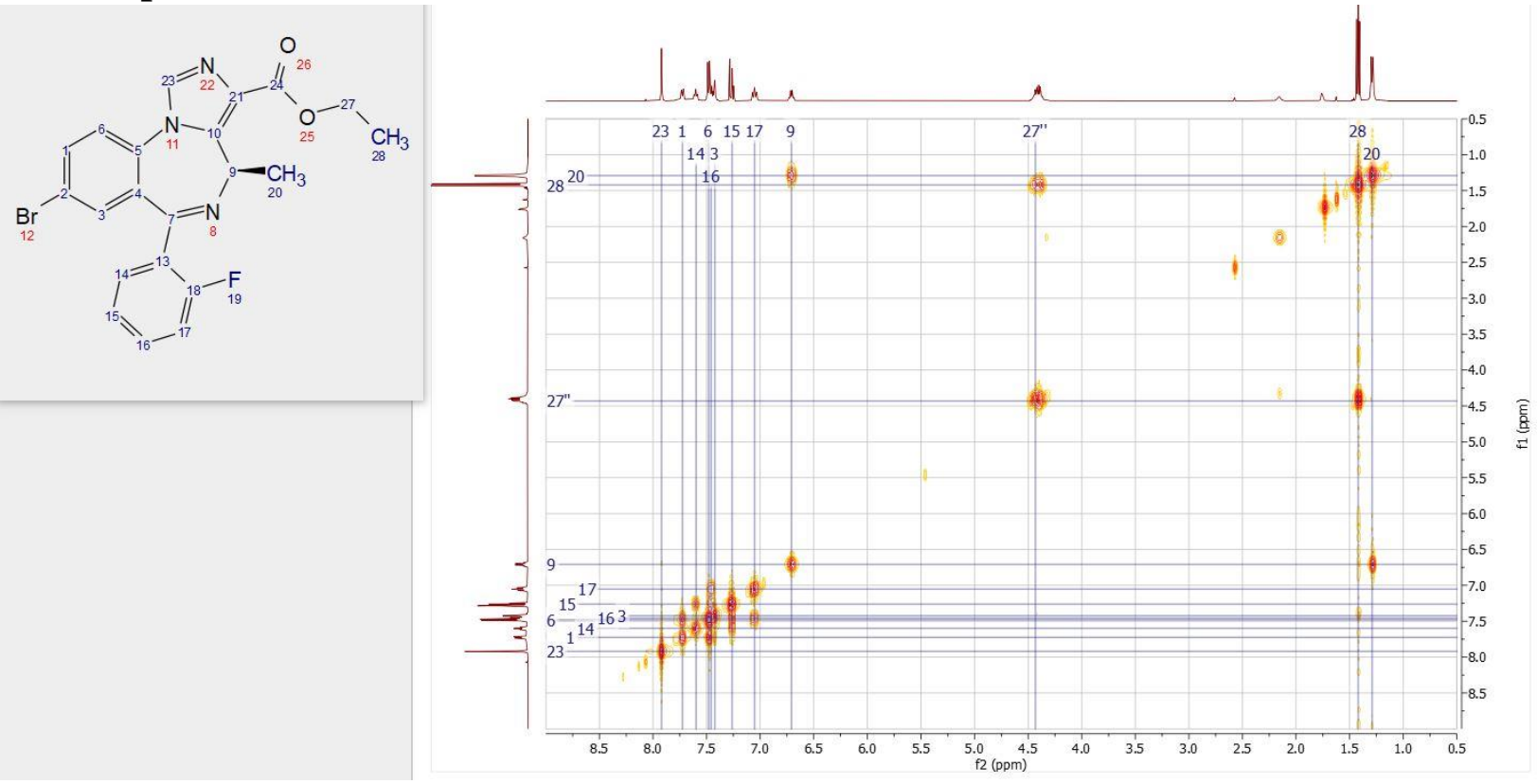

\section{${ }^{1} \mathrm{H}-{ }^{13} \mathrm{C}-\mathrm{HSQC}$ Spectra of 7}
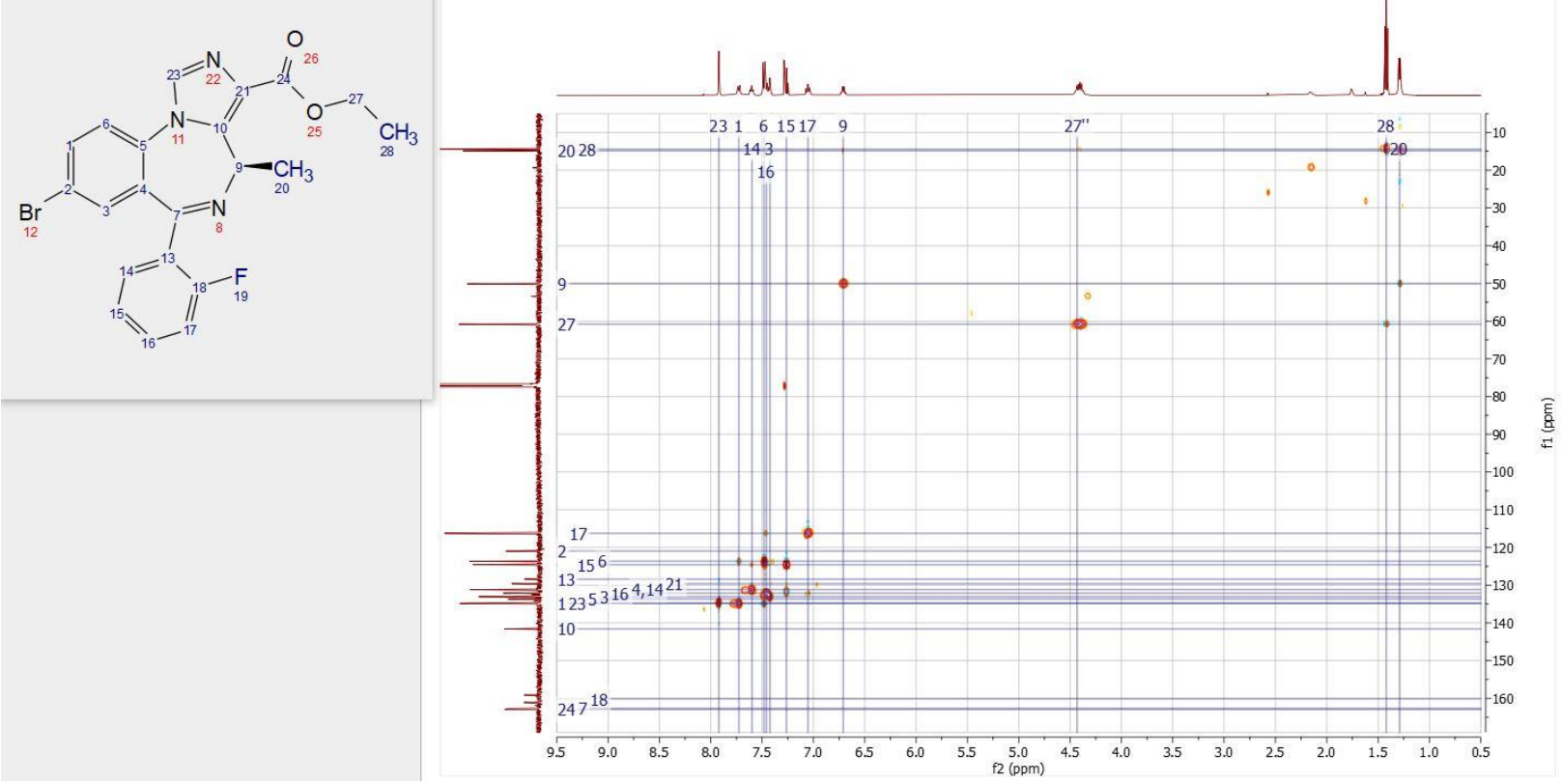


\section{${ }^{1} \mathrm{H}-{ }^{13} \mathrm{C}-\mathrm{HMBC}$ Spectra of 7}

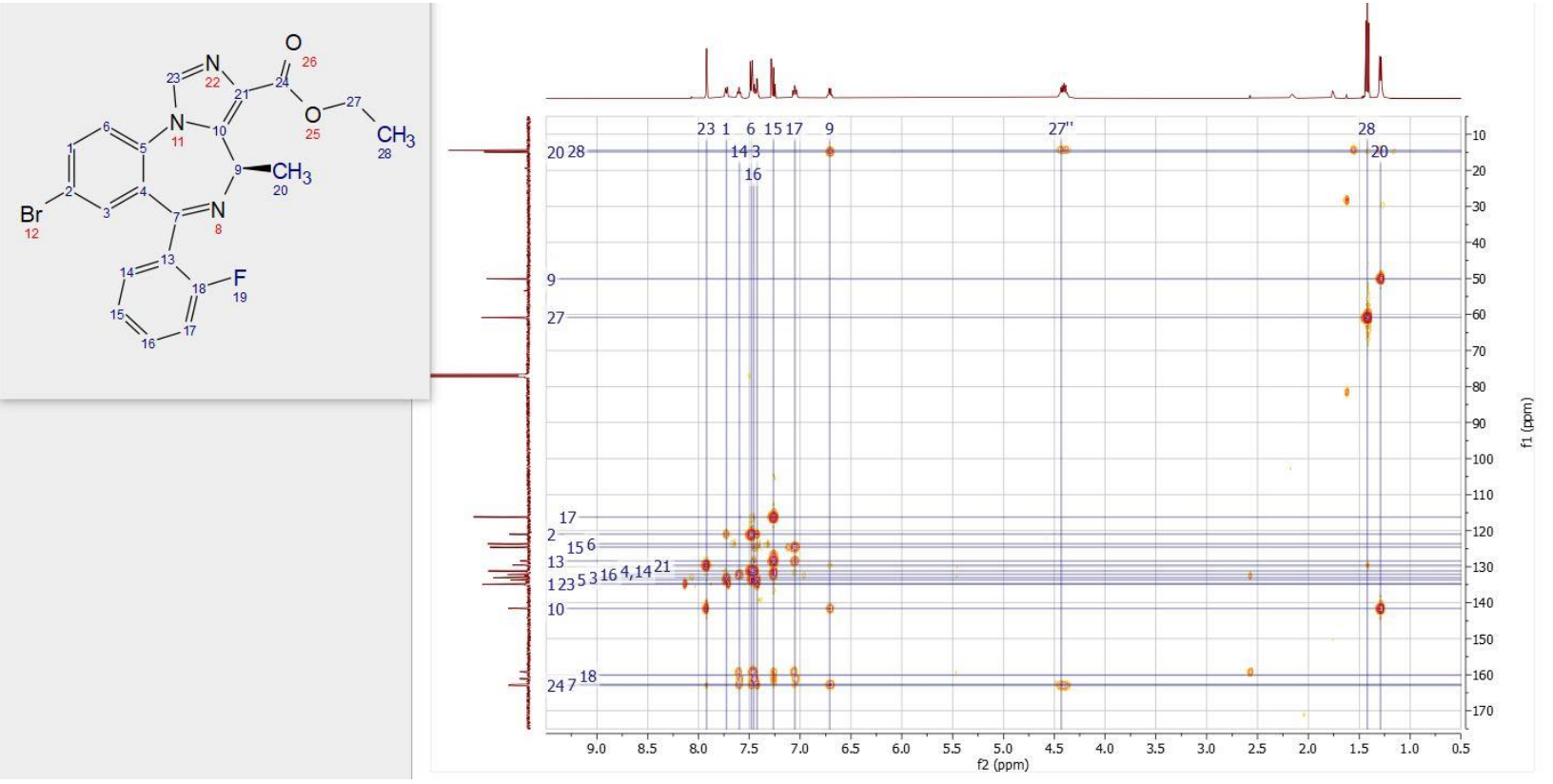




\section{${ }^{1}$ H NMR Spectra of MIDD0301}

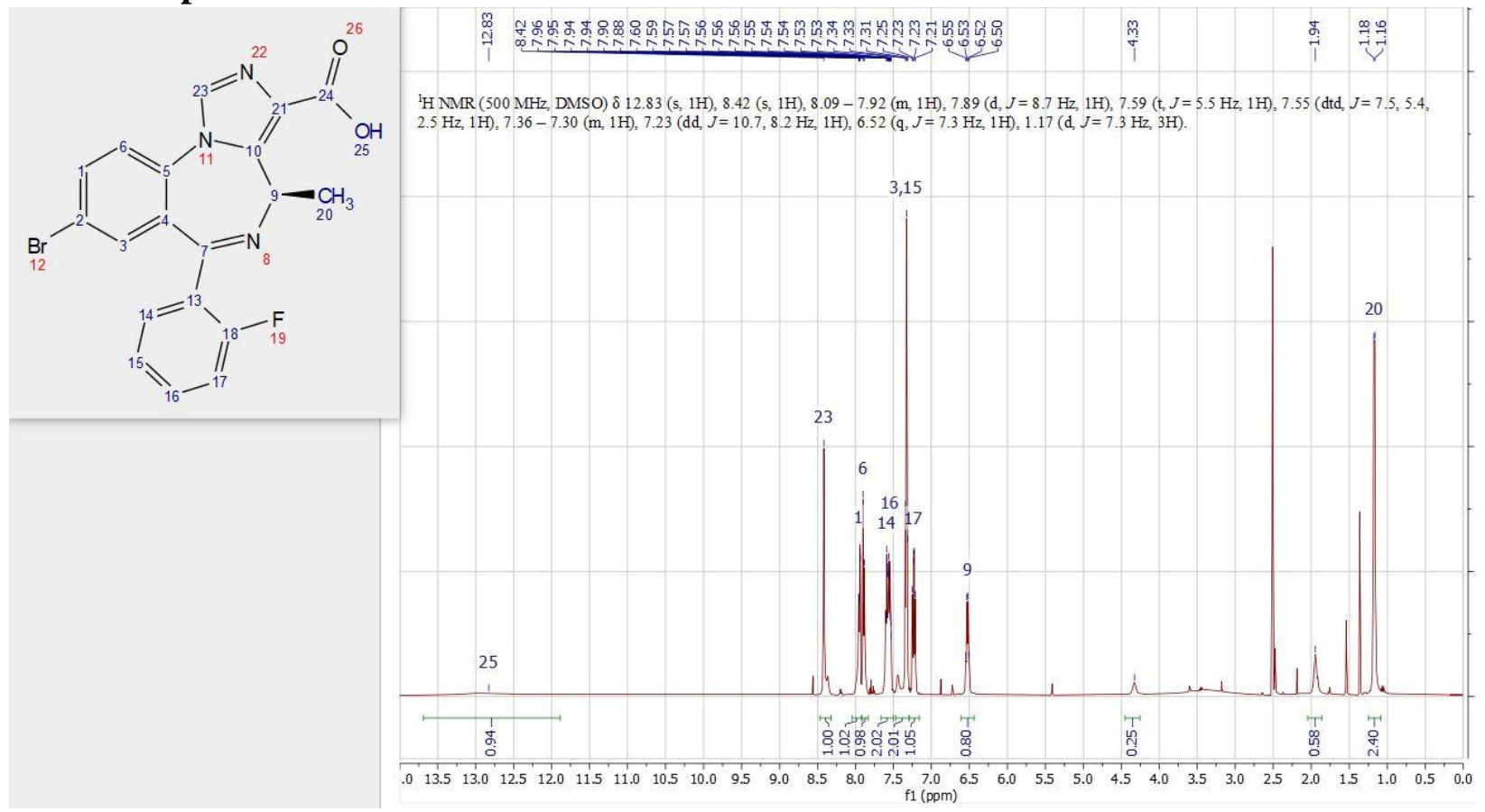

\section{${ }^{13}$ C NMR Spectra of MIDD0301}

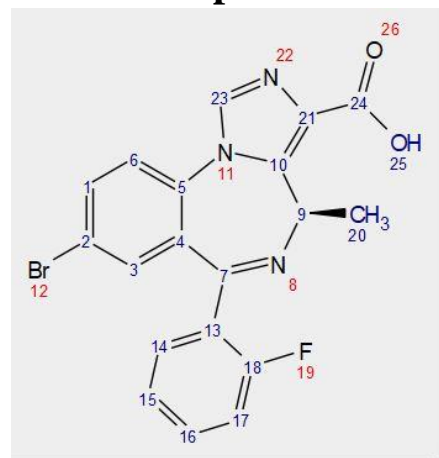

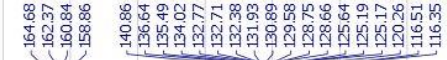

${ }^{13} \mathrm{C}$ NMR (126 MHz, DMSO) $\delta 16468,16237,159.85(\mathrm{~d}, J=2483 \mathrm{~Hz}), 140.86,136.64,135.49,134.02,132.74$ (d $J=7.9 \mathrm{~Hz}), 132,38,131.93,130.89,129.58,128.70(\mathrm{~d}, J=11.7 \mathrm{~Hz}), 125.64,125.18(\mathrm{~d}, J=2.8 \mathrm{~Hz}), 120.26,116.43$ $(\mathrm{d}, J=21.1 \mathrm{~Hz}), 49.83,15.05$.
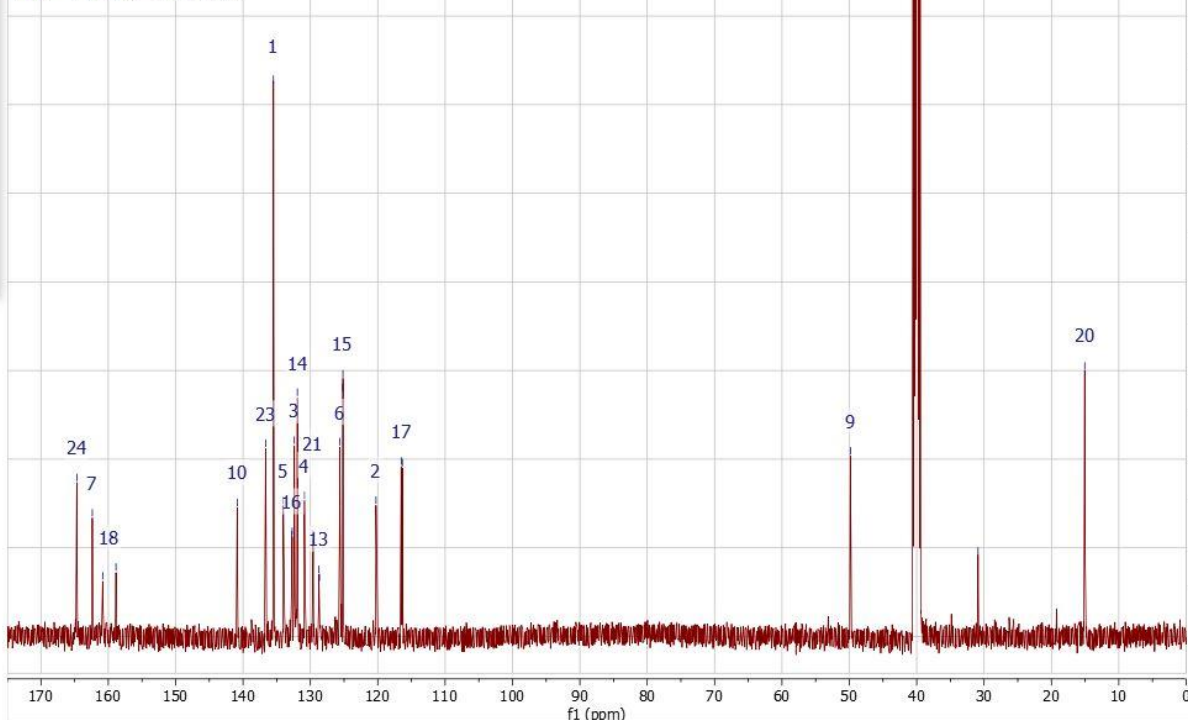


\section{COSY Spectra of MIDD0301}
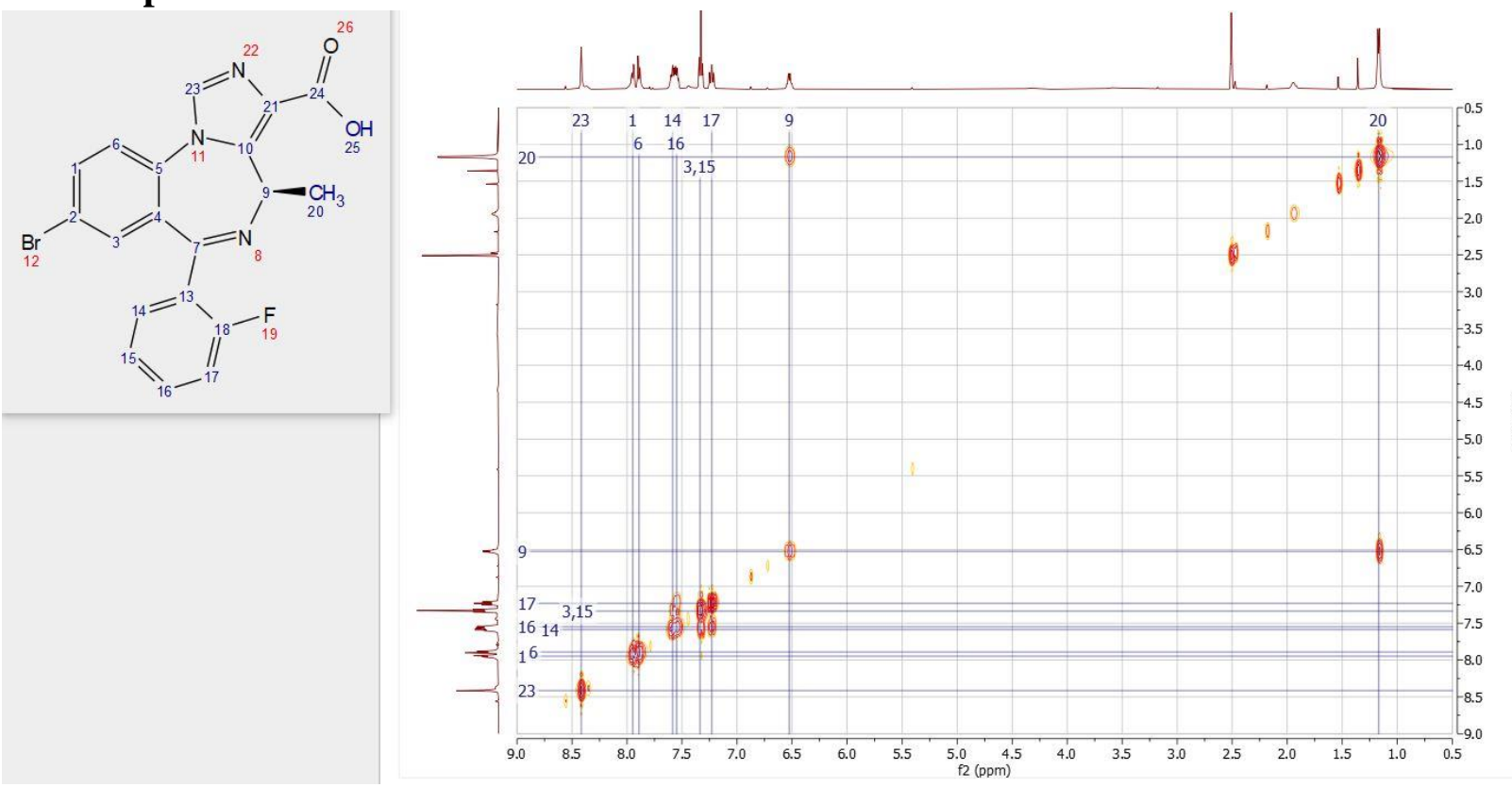

\section{${ }^{1} \mathrm{H}-{ }^{13} \mathrm{C}-\mathrm{HSQC}$ Spectra of MIDD0301}

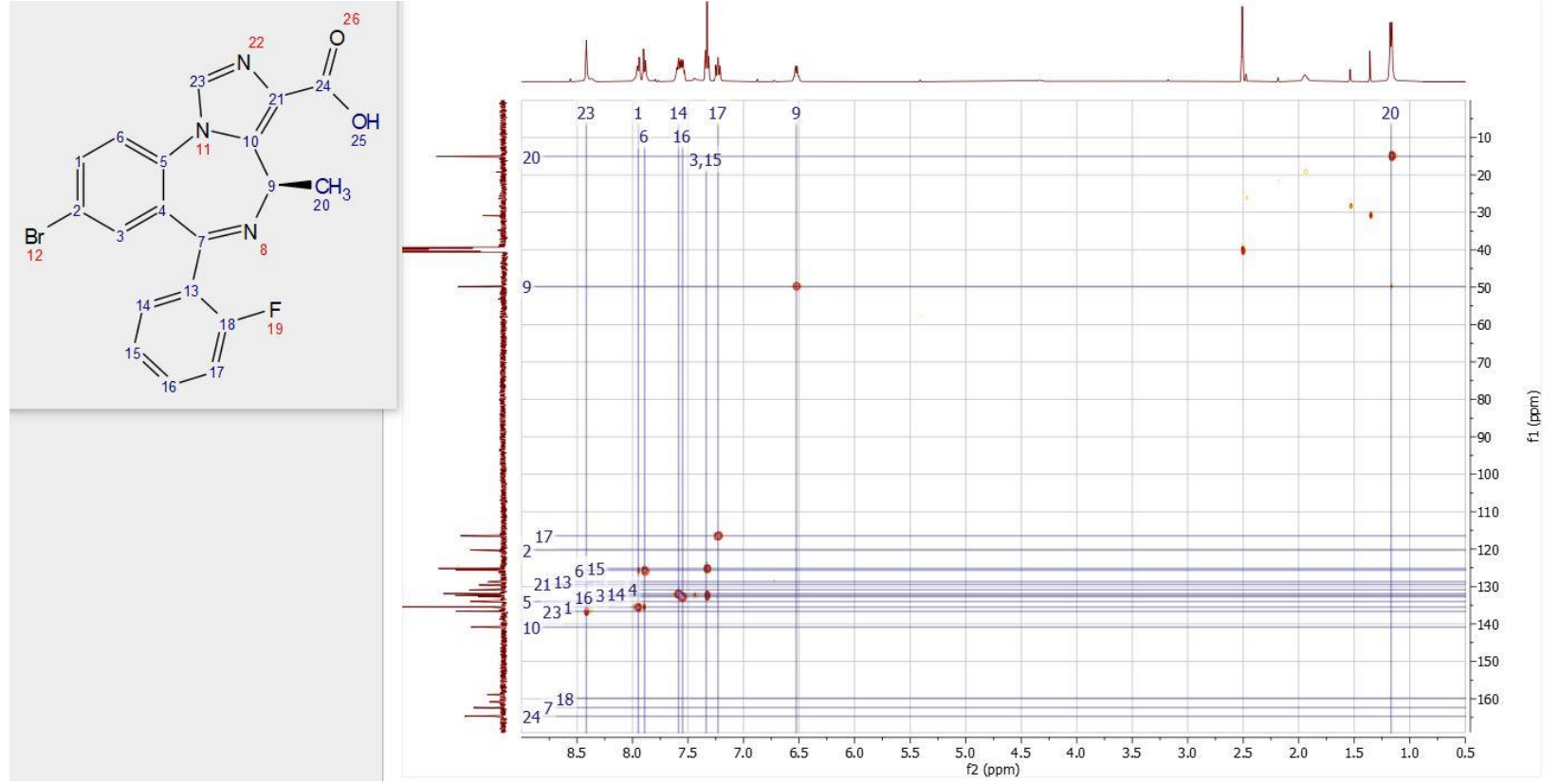




\section{${ }^{1} \mathrm{H}-{ }^{13} \mathrm{C}-\mathrm{HMBC}$ Spectra of MIDD0301}

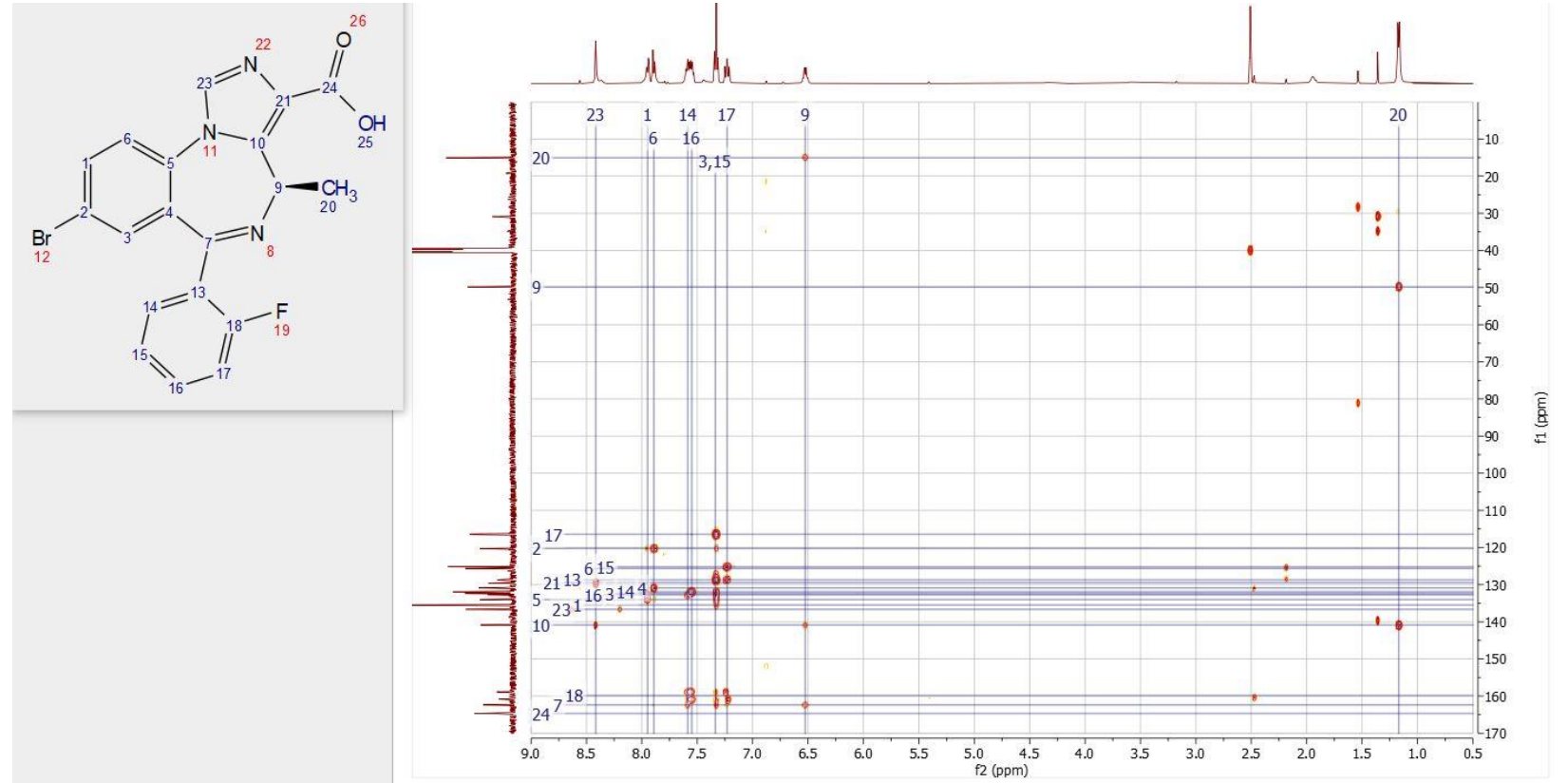

